\title{
Tejido mamario ectópico en vulva: reporte de caso y revisión sistemática de la literatura
}

\section{Ectopic mammary tissue in vullva: case report and systematic literature review}

Sandra Marcela Buitrago-Flechas, $M D^{1}$; Sandra Johana Barrera-Latorre, $\mathrm{MD}^{2}$; Carolina Morante-Caicedo $M^{3}$

Recibido: 13 de agosto del 2020/Aceptado: 4 de agosto del 2021

\section{RESUMEN}

Objetivo: reportar el caso de una paciente con diagnóstico de tejido mamario ectópico en vulva, y realizar una revisión de la literatura acerca del diagnóstico, tratamiento y pronóstico de esta condición en esta localización.

Materiales y métodos: paciente de 49 años consulta por masa vulvar dolorosa a un centro privado de nivel medio de complejidad ubicado en Bogotá, Colombia. Se realizó ecografía de la lesión y posteriormente escisión quirúrgica; la histopatología mostró tejido mamario ectópico sin malignidad. Se realizó una búsqueda en las bases de datos PubMed, Embase, Cochrane, LILACS y Scielo, con las palabras clave "Vulva", "Glándulas mamarias", "ectópico", "Vulva", "Breast" y "Ectopic", y se incluyeron reportes y series de caso de mujeres con tejido mamario en vulva confirmado por histopatología.

Resultados: se identificaron 184 títulos, de los cuales 94 fueron finalmente incluidos para un total

* Correspondencia: Sandra M. Buitrago. Carrera 11 c No 122 - 41. sanbuitrago189@gmail.com

1. Ginecología y Obstetricia. Pontificia Universidad Javeriana, Bogotá (Colombia).

2. Patología Cervical y Colposcopia. Ginecología y Obstetricia. Pontificia Universidad Javeriana, Bogotá (Colombia).

3. Residente Ginecología y Obstetricia. Pontificia Universidad Javeriana, Bogotá (Colombia). de 126 casos. El 57,9\% eran tumores benignos, con un 95\% en mujeres menores de 50 años; y el 42,06\% eran tumores malignos, el $92 \%$ en mujeres mayores de 50 años. El diagnóstico se realizó por clínica, con imágenes diagnósticas complementarias, marcadores tumorales e inmunohistoquímica en algunos casos. Se realizó escisión local en el 91\% de los casos de patología benigna y 43\% de patología maligna, siendo el método diagnóstico y terapéutico. Conclusión: el tejido mamario ectópico en vulva debe ser considerado como parte del diagnóstico diferencial de masas a nivel vulvar con diferente pronóstico en mujeres pre y posmenopáusicas. Se requieren más estudios para una mejor caracterización de la patología y definir el tratamiento ideal en términos de recaída y supervivencia.

Palabras clave: vulva, tejido ectópico, glándula mamaria, mama.

\section{ABSTRACT}

Objective: To report the case of a patient diagnosed with ectopic mammary tissue in the vulva, and to conduct a literature review of the diagnosis, treatment and prognosis of this condition in that location.

Material and methods: A 49-year-old patient who presented with a painful vulvar mass to a private 
intermediate complexity center in Bogotá, Colombia. The lesion was assessed on ultrasound and then surgically excised; histopathology showed ectopic mammary tissue with absence of malignancy. A search was conducted in the PubMed, Embase, Cochrane, LILACS and Scielo databases using the keywords "Vulva," "Breast" and "Ectopic." Case reports and case series of women with histopathology-confirmed mammary tissue in the vulva were included.

Results: Overall, 184 titles were identified and, of these, 94 were ultimately included, for a total of 126 cases, with $57.9 \%$ being benign tumors, 95\% in women under 50 years of age, and $42.06 \%$ being malignant tumors, 92\% in women over 50 years of age. Diagnosis was made on the basis of the clinical findings, with ancillary diagnostic imaging, tumor markers and immunohistochemistry in some cases. Local excision was performed in $91 \%$ of cases with benign pathology and in $43 \%$ of cases with malignant pathology, with the diagnostic method being therapeutic.

Conclusion: Ectopic mammary tissue in the vulva must be considered as part of the differential diagnosis of vulvar masses, prognosis being different in pre and postmenopausal women. Further studies are needed to enhance the characterization of this condition and define the ideal course of treatment in terms of relapse and survival.

Keywords: Vulva, ectopic tissue, mammary gland, breast.

\section{INTRODUCCIÓN}

El tejido mamario ectópico se define como la presencia de glándulas mamarias localizadas fuera de la mama, es una condición que puede encontrarse entre el 2\% y 6\% de la población general (1). Está asociada a la no regresión de la cresta mamaria en el embrión, de la cual solo quedan usualmente los nodos torácicos (2). Se ha clasificado como mama supernumeraria si tiene pezón o areola (o ambos), en combinación con tejido glandular persistente o atrófico, o como tejido aberrante en ausencia de pezón o areola (3). El principal sitio de localización es la axila, donde se ubica el $60 \%$ o 70\% de las lesiones, pero también se han descrito casos a nivel de la vulva, cara, nuca, pecho, espalda media, flanco, caderas, hombro, extremidades superiores y muslos (4). El diagnóstico del tejido mamario ectópico es clínico, apoyado en imágenes diagnósticas y por histopatología. Clínicamente se manifiesta como una masa que puede ser unilateral o bilateral, cuyo tamaño puede fluctuar en relación con cambios hormonales como el embarazo y la lactancia (5). La ecografía es la imagen de elección para la caracterización de masas subcutáneas, ya sean palpables o no $(6,7)$. La apariencia ultrasonográfica del tejido mamario tiene aspecto fibroductal y mezcla de elementos glandulares o grasos. Sirve además para diferenciar el tejido mamario accesorio de lipomas, linfadenopatías, quistes sebáceos, entre otros (8).

El diagnóstico definitivo solo es posible por estudio histopatológico. Típicamente se encuentran glándulas revestidas por epitelio simple cúbico organizadas en conductos y lóbulos. Los conductos están revestidos por células epiteliales y mioepiteliales (4). El enfoque terapéutico es similar al tratamiento de tumores en mama; dependiendo de la localización se debe realizar una escisión completa del tejido ectópico (9). En el caso del carcinoma mamario en tejido ectópico el tratamiento sigue las mismas normas de un carcinoma mamario (10).

Respecto al tejido mamario ectópico de localización vulvar, la primera descripción fue realizada por Hartung en 1872 (11). Hay varias controversias respecto a esta localización del tejido ectópico. Velanovich menciona que es la segunda localización más frecuente después de la de axila (2), mientras que Dordevic indica que es muy raro (12). Algunos autores consideran que su presencia se basa en la falla de la regresión de los nódulos mamarios en el embrión; mientras una segunda teoría se basa en la presencia de glándulas especializadas idénticas a las glándulas mamarias localizadas en la región anogenital como constituyente normal de la vulva a nivel de surcos interlabiales (13). Su diagnóstico diferencial con otras patologías vulvares es difícil, y es susceptible de desarrollar procesos patológicos malignos similares a 
los presentados en el tejido mamario normal, lo que tendría implicaciones para el tratamiento quirúrgico (14), haciendo relevante que el ginecólogo tenga esta condición en mente ante una mujer que consulte por masa vulvar; por lo tanto, el objetivo de la presentación de este caso es hacer una revisión de la literatura sobre su diagnóstico, tratamiento y pronóstico.

\section{REPORTE DE CASO}

Se describe el caso de una paciente multípara de 49 años, en etapa premenopáusica, quien consultó en abril del 2018 por cuadro de cinco meses de evolución, caracterizado por sensación de masa no dolorosa en región vulvar, a un centro de atención ambulatoria privado de mediana complejidad, ubicado en Bogotá, que atiende pacientes del régimen contributivo en el Sistema de seguridad social en Colombia. No informó antecedentes personales o familiares de importancia. En el examen físico, como hallazgo positivo, se encontró a nivel de tercio inferior de labio mayor derecho, lesión nodular de $3,5 \mathrm{~cm}$, sólida, no adherida a planos profundos y sin alteraciones en la piel suprayacente, sin presencia de adenopatías inguinales (ver Figura 1).

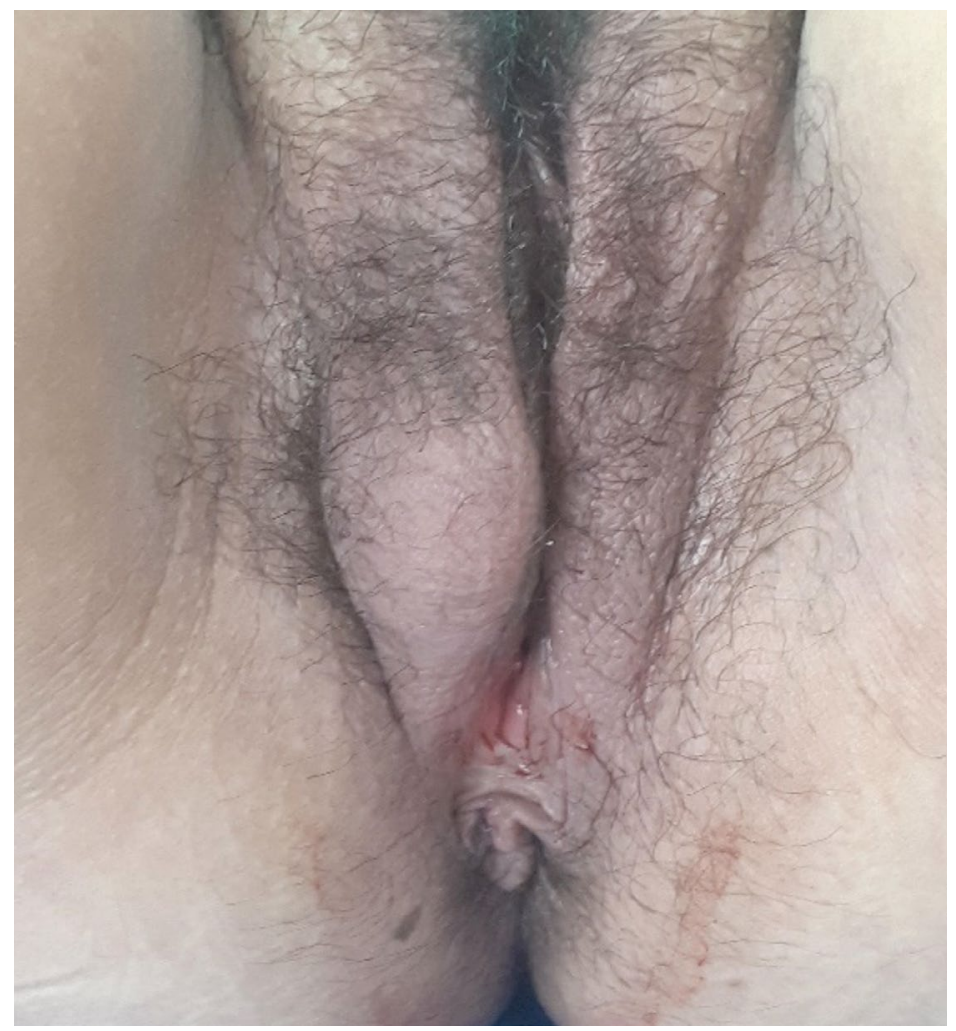

Figura 1. Masa a nivel de labio mayor derecho que corresponde a tejido mamario ectópico. Nótese ausencia de pezón.

Se realizó ultrasonido de tejidos blandos a nivel de vulva, cuyo resultado reportó a nivel del labio mayor derecho imagen redondeada sólida con componente líquido, de contornos bien definidos, reforzamiento posterior y ligera vascularización a la exploración con el Doppler color. Se consideró como primera posibilidad diagnóstica un quiste endometriósico.
La paciente fue llevada a cirugía en mayo de 2018, y bajo anestesia local se realizó extirpación quirúrgica de la lesión. La patología quirúrgica mostró en el examen macroscópico una lesión ovoide de tejido pardo rosado de $2,5 \times 2 \times 1,5 \mathrm{~cm}$ de superficie externa lisa y nodular, al corte con un parénquima pardo claro de aspecto mixoide con áreas arremolinadas (ver Figura 2). El diagnóstico anatomopatológico 
definitivo reportó tejido mamario ectópico en vulva sin displasia ni malignidad.

Se realizó control a los 20 días del postoperatorio, se retiraron los puntos sin complicaciones, la herida quirúrgica continuaba en proceso de cicatrización, sin signos de infección local. La paciente no ha regresado a control después de su primera visita luego del postoperatorio.
Aspectos éticos. Se solicitó la autorización de la paciente con consentimiento informado escrito, a la Clínica Colsubsidio El Lago en Bogotá, Colombia, y al comité de ética institucional para publicar el caso una vez se confirmó el diagnóstico histológico; se tomaron las precauciones para garantizar la confidencialidad de la información y el anonimato de la paciente. El registro fotográfico fue tomado por una de las autoras.

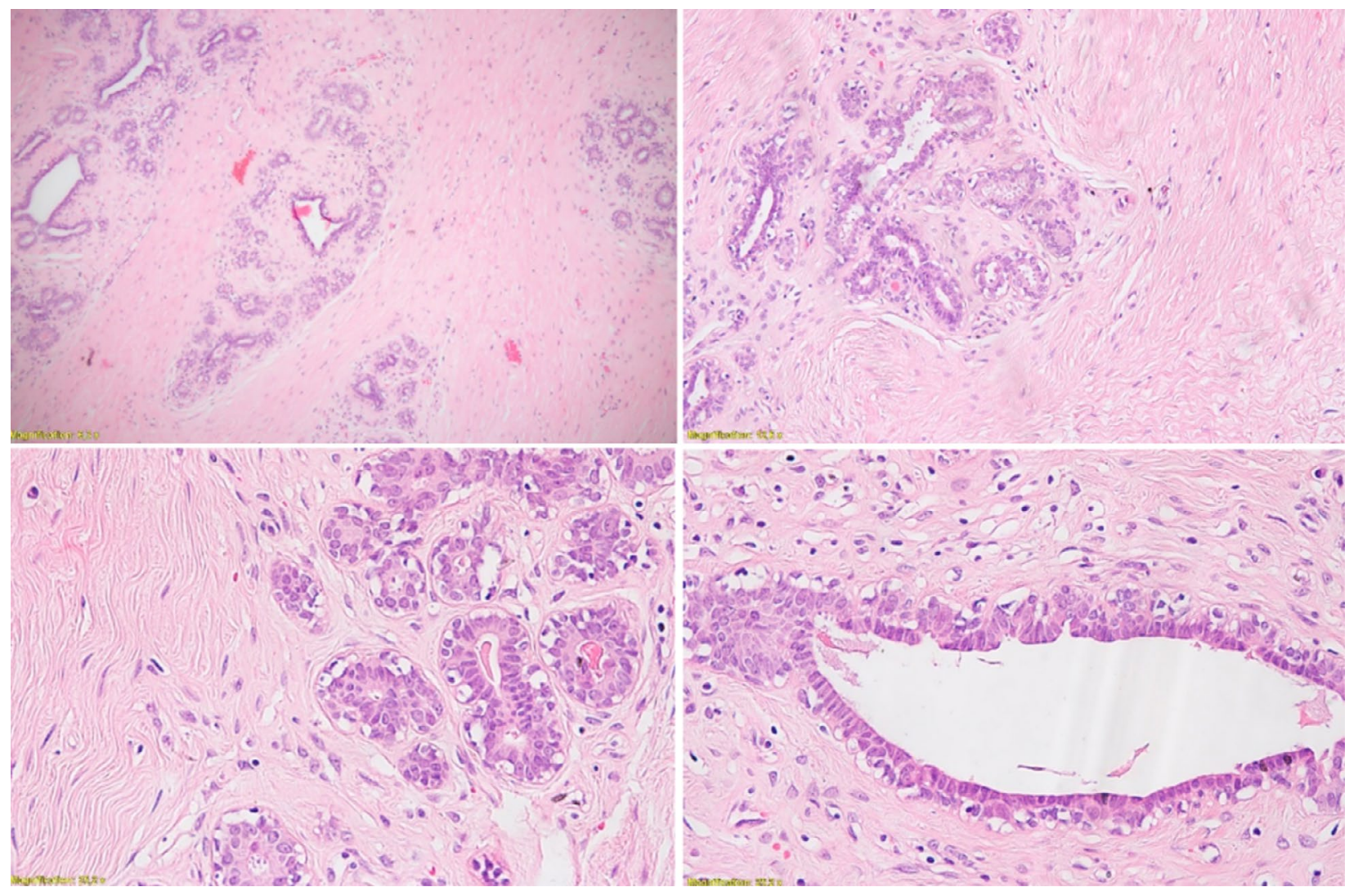

Figura 2. Características microscópicas del tejido mamario ectópico vulvar del caso reportado. Los cortes en H-E a $4 \mathrm{x}-40 \mathrm{x}$ muestran estroma mamario de aspecto usual constituido por conductos grandes, algunos dilatados y lóbulos mamarios, revestidos por una capa de epitelio sobre la base de células musculares lisas. El tejido conectivo intralobulillar es usual, con presencia de algunos fibroblastos.

\section{MATERIALES Y MÉTODOS}

Se realizó una revisión sistemática de la literatura con el fin de describir icómo es la historia natural, el diagnóstico y tratamiento del tejido mamario ectópico en vulva? Se realizó una búsqueda en las bases de datos LILACS y Scielo con las palabras clave "Vulva", "Glándulas mamarias" y "ectópico"; y en Medline vía PubMed, Embase y Cochrane con los términos "Vulva", "Breast" y "Ectopic". Se incluyeron estudios que correspondían a reportes y series de caso, revisiones de la literatura y cartas al editor, de mujeres con tejido mamario ectópico en vulva con confirmación histológica de patología benigna como maligna, y se excluyeron casos de tejido mamario vulvar de origen metastásico. Se limitó la búsqueda a textos en inglés y español publicados 
hasta el 31 de diciembre de 2020. Se buscó información sobre el diagnóstico, tratamiento y pronóstico.

Dos autores (SJB - SMB) realizaron la búsqueda de forma independiente, seleccionando los artículos por título y resumen. Se contactó a los autores vía e-mail cuando fue necesario. Las discrepancias se resolvieron por consenso. La información obtenida en la revisión se organizó mediante un instrumento de recolección de datos que incluyó las siguientes variables y desenlaces: año de publicación, tipo de diseño del estudio, país donde se presentó el caso, edad, estado hormonal de la paciente, tamaño y localización de la lesión, reporte histológico, método diagnóstico, manejo definitivo y tiempo de seguimiento posterior al tratamiento. En los casos con reporte histológico compatible con malignidad se evaluó también la presencia de recaída y supervivencia. Los estudios incluidos fueron clasificados de acuerdo con los niveles de evidencia de la American Diabetes Association (ADA) (15). Se hace síntesis narrativa de la información recolectada.

\section{RESULTADOS}

Se encontraron un total de 184 títulos, de estos, se incluyeron 94 estudios que cumplieron con los criterios de inclusión, los cuales aportaron un total de 126 casos (Figura 3).

\section{Figura 3.}

Diagrama de flujo de la búsqueda bibliográfica y la inclusión de estudios

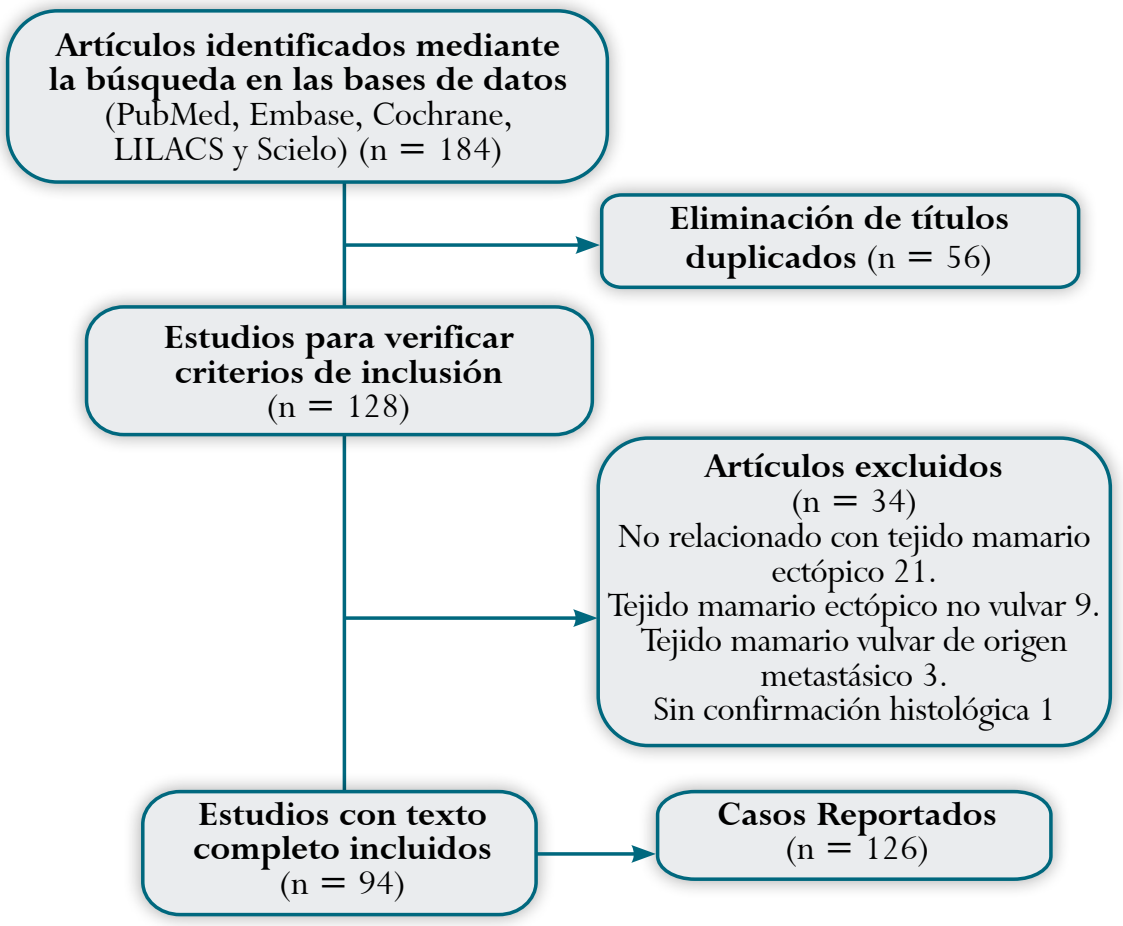

Características de los estudios. De los 94 estudios, 72 corresponden a reportes de caso; de estos, nueve presentan, además, revisión de la literatura. A su vez, se encontraron 22 series de casos, 3 de ellas con revisión de la literatura.

El país con más estudios publicados fue Estados Unidos con un total de 29 estudios que reportan 39 casos, (16-44). Dos estudios fueron informados en Rusia, con 17 casos en total, el primero un reporte de caso (45), y el segundo una serie de casos que aportó 16 pacientes (46). En China se han reportado 5 estudios (47-51), para un total de 7 pacientes; en el Reino Unido se han reportado 6 reportes de caso (52-57); en Turquía (58-61) e Italia (62-65) se han informado 
4 reportes de caso. En Australia (66-68), República Checa (69-71), España (72-74) e India (75-77), cada uno tiene 3 reportes de caso. Canadá $(78,79)$, Japón $(80,81)$, Corea del Sur $(82,83)$, Israel $(84,85)$, Arabia Saudita $(86,87)$ y Kuwait $(88,89)$ tienen 2 reportes de caso cada uno. Por otra parte, Alemania (90), Francia (91), Croacia (92), Austria (93), Holanda (94), Grecia (95), Suiza (96), Portugal (97), Eslovenia (98), Serbia (99), Cuba (100), México (101), Singapur (102), Irán (103), Baréin (104), Nigeria (105), Túnez (106), Brasil (107), Colombia (108) y Chile (109) aportan 1 caso cada país.

Características de la población estudiada. Se encontró un total de 57,9\% de casos (73/126 pacientes) con patología benigna representados en 63 estudios (16, $18,19,21,22,24-26,28,31,35,39,42,45-53,55-58$, $60,61,67,68,70-80,82,83,85-89,91,93-96,99$, $101-103,105,106,108,109)$ y un $42,06 \%$ de casos (53/126 pacientes) con reporte histológico de patología maligna representado en 31 estudios (17, 20, 23, 27, 29 , 30, 32-34, 36-38, 40, 41, 43, 44, 59, 62-66, 80, $81,84,90,92,97,98,104,107)$.

En cuanto a la edad del diagnóstico, hay 68 pacientes menores de 50 años, 9 pacientes entre 50 y 59 años y 47 pacientes con edad igual o mayor a 60 años, y hay 2 estudios en los cuales no se aporta la edad de la paciente en cuestión $(26,94)$.

En el grupo de pacientes menores de 50 años se encontraron 4 casos de patología maligna (17, 29, 32, 65) y 64 casos de patología benigna $(16,18,21,22,24,25$, $28,31,35,39,42,47-58,60,61,67,68,70-79,82,83$, 85-89, 91, 93, 95, 96, 99, 100-103, 105, 106, 108, 109).

En el grupo entre 50 y 59 años se reportaron 7 casos de patología maligna $(44,46,62-64,104,107)$ y 2 de patología benigna (60, 70); y en el grupo de mayores o igual a 60 años se reportaron 42 casos de patología maligna $(20,23,27,30,33,34,36-38,40$, $41,43,44,46,59,66,80,81,84,90,92,97,98$,$) y 5$ casos de patología benigna (19, 45, 46, 69). La edad promedio al momento del diagnóstico de casos de patología benigna fue de 34,1 años, y la edad promedio al momento del diagnóstico de casos de patología maligna fue de 65 años.
El tamaño de la lesión varió entre $0,4 \mathrm{~cm}$ y $40 \mathrm{~cm}$ $(51,79)$. Dentro de la vulva, la localización más frecuente fue en los labios mayores, para un total de 59 pacientes; de estas, 33 se encontraban localizadas en el labio mayor izquierdo $(16,18,20,23,28,29,36,37$, 43, 47, 51, 59-61, 63, 64, 68, 72-75, 81, 83, 84, 88, 91, 95, 98, 99, 100, 102, 109), y 26 en el labio mayor derecho (22, 24-27, 38, 40, 41, 44, 46, 60, 65, 70, 75, $76,80,86,87,90,96,101,104,105)$. Se describieron 5 casos de pacientes con compromiso del clítoris (42, 46, 53, 55, 92), 5 pacientes con afección de los labios menores $(27,32,57,69,97)$ y 3 casos en el surco interlabial derecho $(19,79,107)$. En 41 casos solo se describió la presencia de compromiso vulvar, pero no se describió una localización específica.

La presencia de compromiso en región perineal se describió en 3 pacientes (45, 46, 54), 3 pacientes en región perianal $(46,49), 2$ casos en pubis $(30,34)$ y 1 caso en vagina (66). Además, se encontraron 5 pacientes que presentaron múltiples lesiones en la vulva $(35,39,74,82,89)$.

En el grupo de patología benigna, al momento de vida del diagnóstico (estado hormonal), el 56,1 \% (41/73) se encontraba en edad fértil (16, 25, 31, 39, $46,47,49,51,53-56,58,60,68,71-77,79,83,85$, $87,88,95,99,100,101,103,108,109)$; un $16,4 \%$ $(12 / 73)$ se encontraba en estado de embarazo $(21,22$, $35,47,48,61,78,82,89,91,105)$; un $12,3 \%(9 / 73)$ en período postparto $(18,24,42,52,67,86,93,94,102)$; una en lactancia (106); un 10,9\% (8/73) se encontraba en postmenopausia $(19,28,45,46,57,69,70)$; y un caso sin datos (26).

En cuanto a la descripción de la lesión, solo 2,7\% casos (2/73) informaron la presencia de pezón $(25,50)$; en 4,1\% de casos (3/73) con ausencia de pezón (56, 83, 93); en el resto de los casos no está descrita esta información. Los 5 estudios con casos de múltiples lesiones reportaron patología benigna $(35,39,74,82,89)$.

En el grupo de malignidad, al momento de vida del diagnóstico (estado hormonal), el 94,3\% (50/53) se encontraba en postmenopausia (20, 23, 27, 30, 32-34, 36-38, 40, 41, 43, 44, 46, 59, 62-64, 66, 80, $81,84,90,92,97,98,104,107)$; un 3,7\% (2/53) en 
edad fértil $(29,65)$; y una en premenopausia (17). El tamaño de la lesión varió entre 0,8 y 5 cm $(30,101)$. En el 96,2\% de los casos (51/53) no se reporta la presencia o ausencia de pezón $(17,20,23,27,29,30,32-34$, 36-38, 41, 43, 44, 59, 62-65, 66, 80, 81, 84, 90, 92, $97,104,107)$, y en el $3,7 \%$ de casos $(2 / 53)$ no se tiene información $(46,98)$.

Calificación de la evidencia de los estudios incluidos según la ADA. Todos los estudios fueron calificados como categoría $\mathrm{C}$ por ser reportes o series de casos.

Diagnóstico. El diagnóstico fue clínico dado por la presencia de lesión a nivel vulvar en todos los casos; sin embargo, en múltiples estudios se utilizaron apoyos diagnósticos adicionales tales como ultrasonido, tomografía, marcadores tumorales, marcadores de inmunohistoquímica y biopsia.

En cuanto al diagnóstico imagenológico, se usó la ecografía en un total de 11 casos representados en 9 estudios (16, 35, 47, 50, 54, 82, 83, 93, 109). En 3 casos se utilizó la tomografía de pelvis para una mejor caracterización de la lesión (23, 101, 104), en 3 casos se usó la resonancia de pelvis $(24,66,107)$, y en un caso utilizó la tomografía por emisión de positrones (TEP) (66).

En un total de 30 casos se utilizó la toma de biopsia previo a la escisión quirúrgica (19, 20, 22, 23, 25, 29, 32, 34, 36, 37, 41-44, 47, 55, 59, 62, 63, 66, 75, 78, 79, 81, 89, 100, 101, 103, 104, 107). Se realizaron estudios complementarios con marcadores tumorales en 10 casos, se usaron principalmente: Antígeno carcinoembrionario, Ca 19-9, Ca 125, Ca 15,3 y Alfafetoproteína $(23,34,62-64,66,81,90,92,104)$.

Estudios con técnicas de inmunohistoquímica. Se utilizaron algunas tinciones especiales para diagnóstico de patología mamaria benigna o marcadores tumorales en cáncer de seno, los principalmente usados fueron: receptores hormonales de estrógenos y progesterona, CK7 y GATA3. En un total de 58 casos se reportó el uso de técnicas de inmunohistoquímica representado con 46 estudios $(17,18,20,23,27,29,30,33,34$, 36-41, 44, 45, 51, 52, 58, 61-65, 66, 68, 71, 73, 74, 79, 80-82, 84, 85, 88, 89, 96, 97, 99, 103-105, 107-109); de estos, se encontraron 24 casos con receptores de estrógenos y progesterona positivos $(17,18,20,27,30$, $34,38,40,41,44,51,58,66,73,79,80,84,88,97$, $99,104,105,108)$, y 6 casos únicamente con receptores de estrógenos positivos (23, 37, 62, 81, 107, 109).

El diagnóstico histológico en el grupo de benignidad incluyó el tejido mamario sano, tejido mamario fibroquístico, hidradenoma papilífero, adenomas mamarios, fibroadenomas, adenomas lactógenos y tumores Phyllodes benignos y borderline. La histología más frecuente reportada fue el tejido mamario sano, seguida por los fibroadenomas y el Tumor Phyllodes Benigno (ver Tabla 1). En cuanto a la patología maligna, el diagnóstico histológico incluyó el adenocarcinoma basaloide, adenocarcinoma mucinoso, carcinoma ductal, túbulo-nodular, lobular, adenoide quístico y enfermedad de Paget extramamaria (ver Tabla 1).

Tratamiento. El tratamiento en los casos de patología benigna fue la escisión local en un 91,7\% de los casos $(65 / 73)(16,19,21,22,24-26,28,31,35,39,42,45$, 47-50, 52-58, 60, 61, 67, 69-79, 82, 83, 85-89, 91, 94-96, 99-103, 105, 106, 108, 109), un 2,7\% (2/73) de vulvectomía parcial $(18,51)$, y en un $8.3 \%(6 / 73)$ no se reportaron datos $(46,93)$ (ver Tabla 1$)$.

De los 53 casos reportados de patología maligna se realizó una escisión de la lesión en un 43\% de los casos $(25 / 53)(23,27,33,34,37,38,40,43,80,81$, 90, 92, 97, 98, 104, 107), vulvectomía radical en un $16,98 \%$ de casos $(9 / 53)(17,20,29,32,36,41,59$, $65,84)$; hay un $3,7 \%$ de casos $(2 / 53)$ en los cuales se realiza vulvectomía, sin embargo, no especifican si fue simple o radical $(30,64)$, y en un $7,5 \%$ de casos $(4 / 53)$ se realizaron hemivulvectomías $(44,63)$.

En cuanto a las intervenciones adicionales se realizó linfadenectomías en 30\% de los casos (16/53) (20, 29, 30, 34, 36, 37, 41, 59, 64, 65, 81, 90, 94, 104); radioterapia en un 33\% de casos (18/53) $(23,29,34$, 36, 37, 40, 41, 44, 62, 64, 66, 84, 90, 97, 104, 107); quimioterapia en un 32\% de casos (17/53) (20, 29, 34, 36, 41, 44, 59, 62, 64, 66, 84, 90, 97, 104, 107); hormonoterapia en un 35\% de casos (19/53) (17, 20, 29, 34, 37, 38, 40, 41, 44, 63, 66, 80, 84, 90, 97, 98); y biopsia de ganglio centinela en $11 \%$ de los casos $(6 / 53)$ $(44,63,80,92)$. 
Se reportó solo un caso donde se realizó histerectomía abdominal total, salpingooforectomía bilateral, quimioterapia y radioterapia (62); del mismo modo, se reportó un solo caso donde no se realizó ningún procedimiento quirúrgico. Se llevó a cabo quimioterapia, radioterapia y hormonoterapia (66). En un 20\% de los casos (11/53) no se describe el tratamiento que se les realizó a las pacientes (46).

Pronóstico y seguimiento. En el grupo de patología benigna, solo en un 34,2\% de casos (25/73) de este grupo de pacientes se reportó algún tipo de seguimiento, el cual varió entre uno y noventa y seis meses. De este grupo, se realizó un seguimiento menor de 1 año en el 15\% de los casos (11/73) (21, 39, 47, 48, 51, 67, 72, $75,85,86,102)$; entre 1 a 5 años en el 10,9\% de los $\operatorname{casos}(8 / 73)(70,73,74,75,88,93,101,109)$; mayor a 5 años en el 4,1\% de los casos (3/73) (45, 47, 69); algún tipo de seguimiento (sin embargo, no especifican el tiempo) en el 4,1\% de los casos (3/73) (52, 74, 102); y no se tienen datos en el 65\% de los casos (48/73) reportados $(18,19,22,24,25,26,28,31,35,42,46$, 47, 49, 50, 53-58, 60, 61, 68, 71, 76-79, 82, 83, 87, 89, 91, 94-96, 99, 100, 103, 105, 106, 108). No se reportaron casos de recaídas ni malignización en este grupo de pacientes (ver Tabla 1).

En el grupo de malignidad, el seguimiento varió entre 6 y 120 meses; se realizó un seguimiento menor de 1 año en el 7,5\% de los casos (4/53) (30, 34, 65, 80); entre 1 a 5 años en el 41,5\% de los casos (22/53) (17, $20,27,32,36,37,41,43,44,59,62-64,66,81,84$, 90, 92, 93, 98); mayor a 5 años en el 1,8\% de los casos (1/53) (92); no se tienen datos en el 49\% de los casos (26/53) restantes. Solo se reportó un 11,3\% de los casos (6/53) de pacientes fallecidas entre los 12 y 60 meses de seguimiento $(17,41,43,59,62,66)$ (ver Tabla 1).

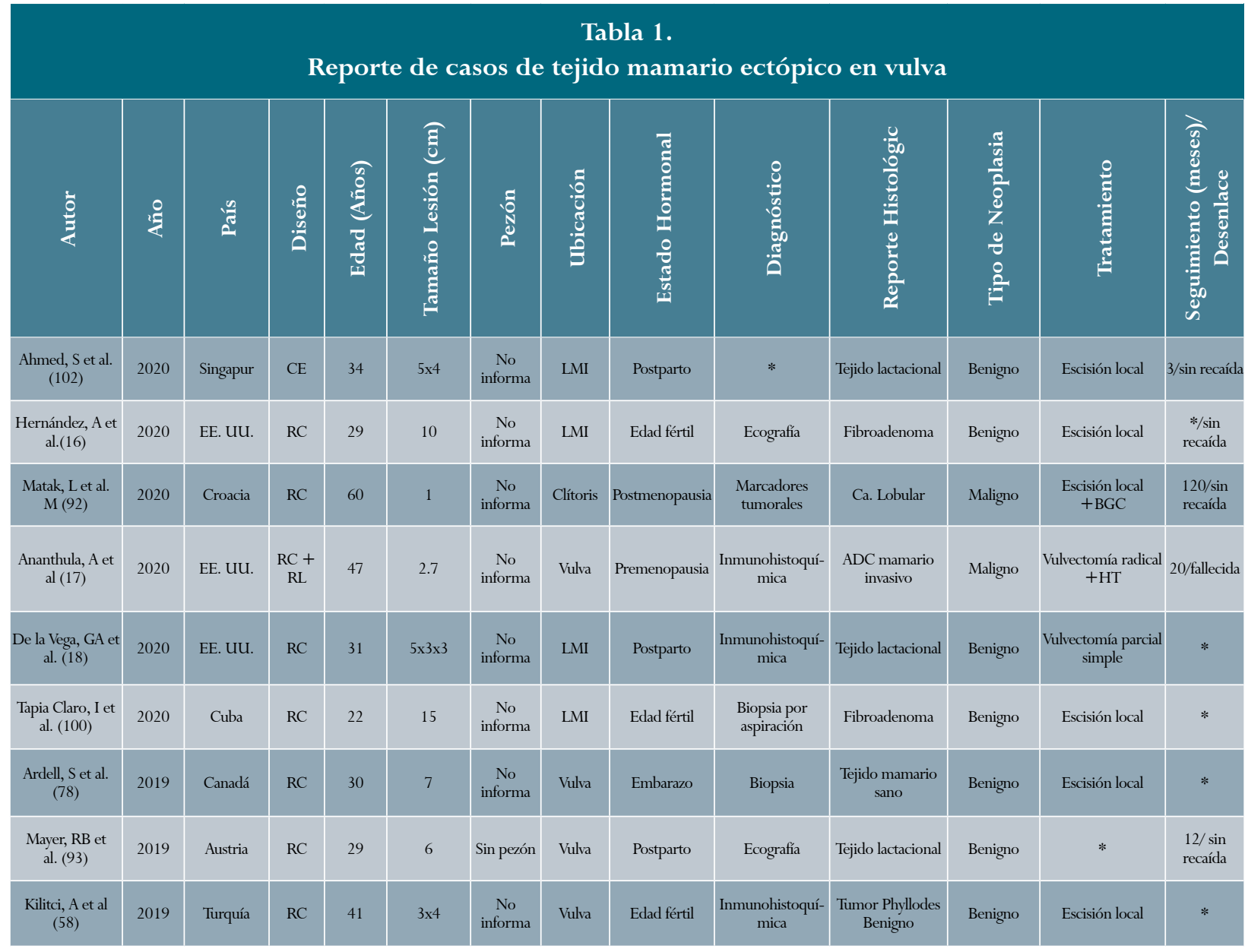




\begin{tabular}{|c|c|c|c|c|c|c|c|c|c|c|c|c|c|}
\hline$\frac{\mathfrak{3}}{2}$ & 选 & $\stackrel{n}{\check{E}}$ & 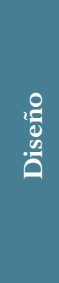 & 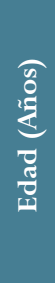 & 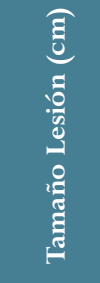 & હే & 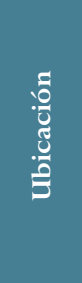 & 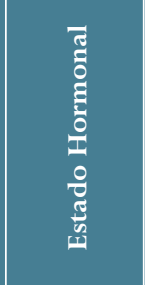 & 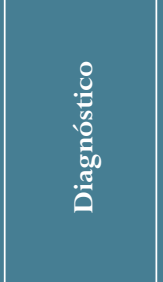 & 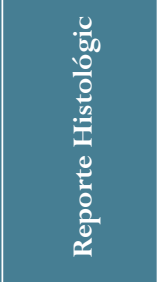 & 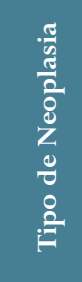 & 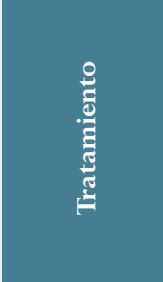 & 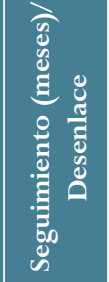 \\
\hline $\begin{array}{l}\text { Mohammadnia, } \\
\text { M et al (103) }\end{array}$ & 2019 & Irán & $\mathrm{RC}$ & 20 & 5 & $\begin{array}{c}\text { No } \\
\text { informa }\end{array}$ & Vulva & Edad fértil & $\begin{array}{c}\text { Biopsia por } \\
\text { aspiración } \\
\text { Inmunohistoquí- } \\
\text { mica }\end{array}$ & Fibroadenoma & Benigno & Escisión local & $*$ \\
\hline \multirow[t]{3}{*}{ Li, G et al. (47) } & 2019 & China & SC & 25 & $5 \times 2 \times 2$ & $\begin{array}{c}\text { No } \\
\text { informa }\end{array}$ & LMI & Edad fértil & Ecografía & Fibroadenoma & Benigno & Escisión local & 6/sin recaída \\
\hline & 2019 & & $\mathrm{SC}$ & 38 & $5.5 \times 4.5 \times 4$ & $\begin{array}{l}\text { No } \\
\text { informa }\end{array}$ & Vulva & Embarazo & $\begin{array}{c}\text { Ecografía y biopsia } \\
\text { por aspiración }\end{array}$ & Fibroadenoma & Benigno & Escisión local & $*$ \\
\hline & 2019 & & SC & 16 & $\begin{array}{c}3.7 \times 3.2 \\
\times 2.5\end{array}$ & $\begin{array}{c}\text { No } \\
\text { informa }\end{array}$ & LMI & Edad fértil & Ecografía & Fibroadenoma & Benigno & Escisión local (x3) & $\begin{array}{l}96 / \text { sin } \\
\text { recaída }\end{array}$ \\
\hline $\begin{array}{c}\text { Guzmán P et al. } \\
\text { (109) }\end{array}$ & 2019 & Chile & $\mathrm{RC}$ & 33 & $4 \times 2$ & $\begin{array}{c}\text { No } \\
\text { informa }\end{array}$ & LMI & Edad fértil & $\begin{array}{c}\text { Ecografía / Inmu- } \\
\text { nohistoquímica }\end{array}$ & Fibroadenoma & Benigno & Escisión local & $\begin{array}{l}12 / \text { sin } \\
\text { recaída }\end{array}$ \\
\hline Actual & 2018 & Colombia & $\mathrm{RC}$ & 49 & 3.5 & NA & LMD & Premenopausia & Clínica & $\begin{array}{c}\text { Tejido mamario } \\
\text { sano }\end{array}$ & Benigno & Escisión local & $*$ \\
\hline $\begin{array}{l}\text { Baradwan, S et } \\
\text { al. (86) }\end{array}$ & 2018 & $\begin{array}{l}\text { Arabia } \\
\text { Saudita }\end{array}$ & $\mathrm{RC}$ & 27 & $6 \times 4$ & $\begin{array}{c}\text { No } \\
\text { informa }\end{array}$ & LMD & Postparto & $*$ & $\begin{array}{c}\text { Tejido mamario } \\
\text { sano }\end{array}$ & Benigno & Escisión local & $1 /$ sin recaída \\
\hline $\begin{array}{l}\text { Al-Mansouri, L et } \\
\text { Al. (66) }\end{array}$ & 2018 & Australia & $\begin{array}{l}\mathrm{RCY} \\
\mathrm{RL}\end{array}$ & 76 & $*$ & $\begin{array}{c}\text { No } \\
\text { informa }\end{array}$ & Vagina & Postmenopausia & $\begin{array}{c}\text { Biopsia por } \\
\text { aspiración/ Inmu- } \\
\text { nohistoquímica } \\
\text { Marcadores } \\
\text { tumorales RM de } \\
\text { pelvis y TEP }\end{array}$ & ADC metastásico & Maligno & $\mathrm{RT}+\mathrm{QT}+\mathrm{HT}$ & 60/fallecida \\
\hline $\begin{array}{l}\text { Lopes A et al. } \\
\quad(107)\end{array}$ & 2018 & Brasil & $\mathrm{RC}$ & 58 & 1.2 & $\begin{array}{c}\text { No } \\
\text { informa }\end{array}$ & SID & Postmenopausia & $\begin{array}{l}\text { Biopsia / Inmuno- } \\
\text { histoquímica RM } \\
\text { de pelvis }\end{array}$ & $\begin{array}{l}\text { Ca. Mamario } \\
\text { invasivo }\end{array}$ & Maligno & $\begin{array}{c}\text { Escisión + QT } \\
+\mathrm{RT}\end{array}$ & $*$ \\
\hline $\begin{array}{c}\text { Moulla A et al. } \\
\text { (52) }\end{array}$ & 2017 & Reino unido & $\mathrm{RC}$ & 32 & $5 \times 3$ & $\begin{array}{c}\text { No } \\
\text { informa }\end{array}$ & Vulva & Postparto & $\begin{array}{l}\text { Inmunohistoquí- } \\
\text { mica }\end{array}$ & $\begin{array}{c}\text { Tumor Phyllodes } \\
\text { Benigno }\end{array}$ & Benigno & Escisión local & $\begin{array}{l}\text { */Sin } \\
\text { recaída }\end{array}$ \\
\hline Sluga M (94) & 2017 & Holanda & $\mathrm{RC}$ & $*$ & $*$ & * & Vulva & Postparto & $*$ & $\begin{array}{l}\text { Tejido mamario } \\
\text { quístico }\end{array}$ & Benigno & Escisión local & * \\
\hline \multirow[t]{10}{*}{$\begin{array}{c}\text { Konstantinova A } \\
\text { et al. (46) }\end{array}$} & 2017 & Rusia & SC & 71 & $*$ & $\begin{array}{c}\text { No } \\
\text { informa }\end{array}$ & Clítoris & Postmenopausia & $*$ & $\begin{array}{l}\text { Enf. Paget Extra- } \\
\text { mamaria }\end{array}$ & Maligno & $*$ & * \\
\hline & 2017 & & $\mathrm{SC}$ & 76 & $*$ & $\begin{array}{c}\text { No } \\
\text { informa }\end{array}$ & Vulva & Postmenopausia & $*$ & $\begin{array}{l}\text { Enf. Paget Extra- } \\
\text { mamaria }\end{array}$ & Maligno & $*$ & $*$ \\
\hline & 2017 & & SC & 64 & * & $\begin{array}{c}\text { No } \\
\text { informa }\end{array}$ & Vulva & Postmenopausia & $*$ & $\begin{array}{l}\text { Enf. Paget Extra- } \\
\text { mamaria }\end{array}$ & Maligno & $*$ & $*$ \\
\hline & 2017 & & SC & 78 & * & $\begin{array}{c}\text { No } \\
\text { informa }\end{array}$ & Vulva & Postmenopausia & * & $\begin{array}{l}\text { Enf. Paget Extra- } \\
\text { mamaria }\end{array}$ & Maligno & $*$ & $*$ \\
\hline & 2017 & & SC & 82 & $*$ & $\begin{array}{c}\text { No } \\
\text { informa }\end{array}$ & Perianal & Postmenopausia & $*$ & $\begin{array}{l}\text { Enf. Paget Extra- } \\
\text { mamaria }\end{array}$ & Maligno & $*$ & * \\
\hline & 2017 & & SC & 68 & $*$ & $\begin{array}{c}\text { No } \\
\text { informa }\end{array}$ & Vulva & Postmenopausia & $*$ & $\begin{array}{l}\text { Enf. Paget Extra- } \\
\text { mamaria }\end{array}$ & Maligno & $*$ & * \\
\hline & 2017 & & SC & 77 & $*$ & $\begin{array}{c}\text { No } \\
\text { informa }\end{array}$ & Vulva & Postmenopausia & $*$ & $\begin{array}{l}\text { Enf. Paget Extra- } \\
\text { mamaria }\end{array}$ & Maligno & $*$ & * \\
\hline & 2017 & & SC & 68 & $*$ & $\begin{array}{c}\text { No } \\
\text { informa }\end{array}$ & Periné & Postmenopausia & $*$ & $\begin{array}{c}\text { Enf. Paget Extra- } \\
\text { mamaria }\end{array}$ & Maligno & $*$ & * \\
\hline & 2017 & & SC & 54 & $*$ & $\begin{array}{c}\text { No } \\
\text { informa }\end{array}$ & Perianal & Postmenopausia & $*$ & $\begin{array}{l}\text { Ca. Adenoide } \\
\text { Quístico }\end{array}$ & Maligno & $*$ & $*$ \\
\hline & 2017 & & SC & 64 & $*$ & $\begin{array}{c}\text { No } \\
\text { informa }\end{array}$ & Vulva & Postmenopausia & $*$ & Ca. Tubulobular & Maligno & $*$ & $*$ \\
\hline
\end{tabular}




\begin{tabular}{|c|c|c|c|c|c|c|c|c|c|c|c|c|c|}
\hline$\stackrel{\grave{2}}{\frac{\partial}{2}}$ & 递 & है & $\begin{array}{l}\stackrel{0}{\frac{\pi}{8}} \\
.00 \\
0\end{array}$ & 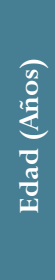 & 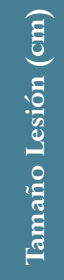 & ֻే & $\begin{array}{l}\frac{5}{0} \\
\frac{7}{8} \\
\frac{8}{3} \\
\frac{1}{3}\end{array}$ & 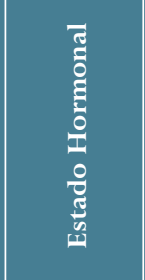 & 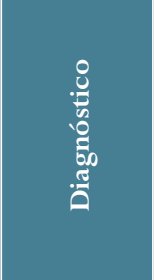 & $\begin{array}{l}\frac{0}{0} \\
0 \\
\frac{0}{0} \\
\frac{0}{2} \\
\frac{0}{2} \\
0 \\
\frac{0}{0} \\
\frac{0}{0} \\
\simeq\end{array}$ & 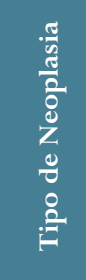 & 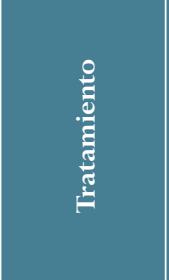 & 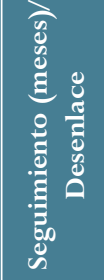 \\
\hline & 2017 & & $\mathrm{SC}$ & 61 & $*$ & $\begin{array}{c}\text { No } \\
\text { informa }\end{array}$ & LMD & Postmenopausia & $*$ & Ca. ductal invasivo & Maligno & $*$ & $*$ \\
\hline & 2017 & & $\mathrm{SC}$ & 77 & $*$ & $\begin{array}{c}\text { No } \\
\text { informa }\end{array}$ & Vulva & Postmenopausia & $*$ & $\begin{array}{l}\text { Hidradenoma } \\
\text { Papilifero }\end{array}$ & Benigno & $*$ & $*$ \\
\hline & 2017 & & SC & 45 & $*$ & $\begin{array}{c}\text { No } \\
\text { informa }\end{array}$ & Vulva & Edad fértil & $*$ & $\begin{array}{l}\text { Hidradenoma } \\
\text { Papilifero }\end{array}$ & Benigno & $*$ & $*$ \\
\hline & 2017 & & SC & 25 & * & $\begin{array}{c}\text { No } \\
\text { informa }\end{array}$ & Vulva & Edad fértil & $*$ & $\begin{array}{l}\text { Hidradenoma } \\
\text { Papilifero }\end{array}$ & Benigno & $*$ & $*$ \\
\hline & 2017 & & $\mathrm{SC}$ & 37 & * & $\begin{array}{c}\text { No } \\
\text { informa }\end{array}$ & Vulva & Edad fértil & $*$ & $\begin{array}{l}\text { Hidradenoma } \\
\text { Papilifero }\end{array}$ & Benigno & $*$ & $*$ \\
\hline & 2017 & & SC & 80 & $*$ & $\begin{array}{c}\text { No } \\
\text { informa }\end{array}$ & Vulva & Postmenopausia & $*$ & $\begin{array}{l}\text { Hidradenoma } \\
\text { Papilifero }\end{array}$ & Benigno & $*$ & $*$ \\
\hline $\begin{array}{l}\text { Mikhael S et al. } \\
\text { (19) }\end{array}$ & 2018 & Colombia & $\mathrm{RC}$ & 49 & 3.5 & $\begin{array}{c}\text { No } \\
\text { informa }\end{array}$ & SID & Postmenopausia & Biopsia & $\begin{array}{c}\text { Tejido mamario } \\
\text { sano }\end{array}$ & Benigno & Escisión local & * \\
\hline $\begin{array}{c}\text { Zhou M et al. } \\
(48)\end{array}$ & EE. UU. & $\mathrm{RC}$ & 69 & $2 \times 1$ & $4 \times 2$ & $\begin{array}{c}\text { No } \\
\text { informa }\end{array}$ & Vulva & Embarazo & $*$ & $\begin{array}{c}\text { Tejido mamario } \\
\text { sano }\end{array}$ & Benigno & Escisión local & $1 /$ sin recaída \\
\hline $\begin{array}{c}\text { Ishigaki T et al. } \\
(80)\end{array}$ & 2017 & Japón & $\mathrm{RC}$ & 72 & 1.5 & $\begin{array}{c}\text { No } \\
\text { informa }\end{array}$ & LMD & Postmenopausia & $\begin{array}{l}\text { Inmunohistoquí- } \\
\text { mica }\end{array}$ & Ca. ductal invasivo & Maligno & $\begin{array}{l}\text { Escisión + } \\
\text { BGC+HT }\end{array}$ & 6/sin recaída \\
\hline \multirow[t]{3}{*}{$\begin{array}{l}\text { Kredentser AM et } \\
\text { al. (44) }\end{array}$} & 2017 & EE. UU. & SC Y RL & 75 & 1 & $\begin{array}{c}\text { No } \\
\text { informa }\end{array}$ & LMD & Postmenopausia & $\begin{array}{l}\text { Inmunohistoquí- } \\
\text { mica }\end{array}$ & $\begin{array}{l}\text { ADC mamario } \\
\text { invasivo }\end{array}$ & Maligno & $\begin{array}{c}\text { Hemivulvectomia } \\
\text { radical derecha } \\
+ \text { BGC+RT+ } \\
\text { QT+HT }\end{array}$ & $\begin{array}{l}48 / \text { sin } \\
\text { recaída }\end{array}$ \\
\hline & 2017 & & SC Y RL & 59 & 0.9 & $\begin{array}{c}\text { No } \\
\text { informa }\end{array}$ & LMD & Postmenopausia & $\begin{array}{l}\text { Biopsia / Inmuno- } \\
\text { histoquímica }\end{array}$ & ADC mucinoso & Maligno & $\begin{array}{c}\text { Hemivulvec- } \\
\text { tomia radical } \\
\text { derecha }+ \text { BGC+ } \\
\text { RT+QT+HT }\end{array}$ & $\begin{array}{l}48 / \text { sin } \\
\text { recaída }\end{array}$ \\
\hline & 2017 & & SC Y RL & 67 & 3 & $\begin{array}{c}\text { No } \\
\text { informa }\end{array}$ & LMD & Postmenopausia & $\begin{array}{l}\text { Inmunohistoquí- } \\
\text { mica }\end{array}$ & $\begin{array}{l}\text { ADC mamario } \\
\text { invasivo }\end{array}$ & Maligno & $\begin{array}{c}\text { Hemivulvectomia } \\
\text { radical derecha }+ \\
\text { BGC+ HT }\end{array}$ & $\begin{array}{l}36 / \text { sin } \\
\text { recaída }\end{array}$ \\
\hline $\begin{array}{l}\text { Del Vecchio V et } \\
\text { al. (62) }\end{array}$ & 2018 & Colombia & $\mathrm{RC}$ & 49 & 3.5 & $\mathrm{NA}$ & LMD & Premenopausia & $\begin{array}{l}\text { Biopsia/ Marcado- } \\
\text { res tumorales } \\
\text { Inmunohistoquí- } \\
\text { mica }\end{array}$ & ADC Basaloide & Maligno & $\begin{array}{c}\mathrm{HAT}+\mathrm{SOB}+ \\
\text { QT }+\mathrm{RT}\end{array}$ & 18/fallecida \\
\hline $\begin{array}{c}\text { Baykal C et al. } \\
\text { (59) }\end{array}$ & 2015 & Turquía & $\mathrm{RC}$ & 73 & $*$ & $\begin{array}{c}\text { No } \\
\text { informa }\end{array}$ & LMI & Postmenopausia & Biopsia & Ca. Mamario & Maligno & $\begin{array}{c}\text { Vulvectomía radical } \\
\text { + L+ QT }\end{array}$ & 12/fallecida \\
\hline Cripe J et al. (20) & 2015 & EE. UU. & RC y RL & 62 & 1.3 & $\begin{array}{c}\text { No } \\
\text { informa }\end{array}$ & LMI & Postmenopausia & $\begin{array}{l}\text { Biopsia / inmuno- } \\
\text { histoquímica }\end{array}$ & Ca. ductal invasivo & Maligno & $\begin{array}{c}\text { Vulvectomía radical } \\
\text { parcial + L+ } \\
\text { QT+HT }\end{array}$ & $\begin{array}{l}13 / \text { sin } \\
\text { recaída }\end{array}$ \\
\hline \multirow[t]{2}{*}{$\begin{array}{c}\text { Kalyani R et al. } \\
\text { (75) }\end{array}$} & 2014 & India & $\mathrm{RC}$ & 26 & $4 \times 2$ & $\begin{array}{c}\text { No } \\
\text { informa }\end{array}$ & LMD & Edad fértil & $\begin{array}{l}\text { Biopsia por } \\
\text { aspiración }\end{array}$ & Fibroadenoma & Benigno & Escisión local & $\begin{array}{l}12 / \text { sin } \\
\text { recaída }\end{array}$ \\
\hline & 2014 & & $\mathrm{RC}$ & 45 & $12 \times 8$ & $\begin{array}{c}\text { No } \\
\text { informa }\end{array}$ & LMI & Edad fértil & $*$ & Fibroadenoma & Benigno & Escisión local & $\begin{array}{l}10 / \text { sin } \\
\text { recaída }\end{array}$ \\
\hline $\begin{array}{c}\text { Arshad W et al. } \\
(49)\end{array}$ & 2014 & China & $\mathrm{RC}$ & 28 & 0.8 & $*$ & Perianal & Edad fértil & $*$ & $\begin{array}{l}\text { Adenoma } \\
\text { mamario }\end{array}$ & Benigno & Escisión local & $*$ \\
\hline $\begin{array}{c}\text { Al-Badawi IA } \\
\text { (87) }\end{array}$ & 2014 & $\begin{array}{l}\text { Arabia } \\
\text { Saudita }\end{array}$ & IM & 48 & $7 \times 4$ & $\begin{array}{c}\text { No } \\
\text { informa }\end{array}$ & LMD & Edad fértil & $*$ & $\begin{array}{c}\text { Tejido mamario } \\
\text { sano }\end{array}$ & Benigno & Escisión local & * \\
\hline $\begin{array}{l}\text { Konstantinova } \\
\text { AM et al. (69) }\end{array}$ & 2014 & $\begin{array}{l}\text { República } \\
\text { Checa }\end{array}$ & $\mathrm{RC}$ & 63 & $1 \times 0.5$ & $\begin{array}{c}\text { No } \\
\text { informa }\end{array}$ & $\mathrm{LMi}$ & Postmenopausia & $*$ & Fibroadenoma & Benigno & Escisión local & $\begin{array}{l}84 / \text { sin } \\
\text { recaída }\end{array}$ \\
\hline
\end{tabular}

Continuación Tabla 1 


\begin{tabular}{|c|c|c|c|c|c|c|c|c|c|c|c|c|c|}
\hline 巳̆丶 & 원 & है & 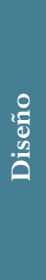 & 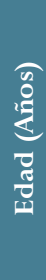 & 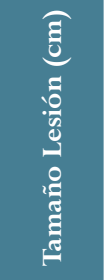 & อี & 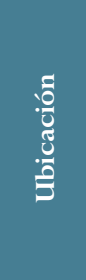 & 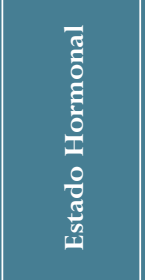 & 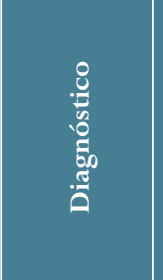 & 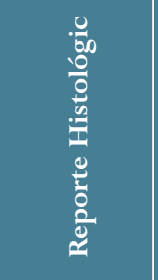 & 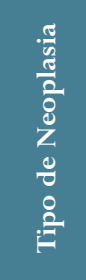 & 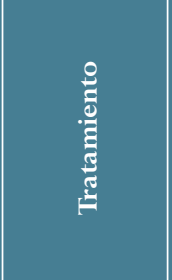 & 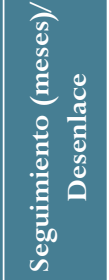 \\
\hline $\begin{array}{c}\text { Jiménez GA et al. } \\
\qquad(108)\end{array}$ & 2014 & Colombia & $\mathrm{RC}$ & 42 & $3 \times 3$ & $\begin{array}{l}\text { No } \\
\text { informa }\end{array}$ & Vulva & Edad fértil & $\begin{array}{l}\text { Inmunohistoquí- } \\
\text { mica }\end{array}$ & Fibroadenoma & Benigno & Escisión local & $*$ \\
\hline $\begin{array}{l}\text { Zhang Z et al. } \\
\text { (50) }\end{array}$ & 2014 & China & $\mathrm{RC}$ & 25 & $6 \times 5$ & Con pezón & Vulva & Embarazo & Ecografía & $\begin{array}{c}\text { Tejido mamario } \\
\text { sano }\end{array}$ & Benigno & Escisión local & $*$ \\
\hline $\begin{array}{c}\text { Leodara V et al. } \\
\text { (95) }\end{array}$ & 2014 & Grecia & $\mathrm{RC}$ & 42 & 2.5 & $*$ & LMI & Edad fértil & $*$ & $\begin{array}{l}\text { Phyllodes Bor- } \\
\text { derline }\end{array}$ & Benigno & Escisión local & $*$ \\
\hline $\begin{array}{l}\text { Wagner IJ et } \\
\text { al.(21) }\end{array}$ & 2013 & EE. UU. & $\mathrm{RC}$ & 23 & 6 & $\begin{array}{l}\text { No } \\
\text { informa }\end{array}$ & Vulva & Embarazo & $*$ & $\begin{array}{c}\text { Tejido mamario } \\
\text { sano }\end{array}$ & Benigno & Escisión local & $5 /$ sin recaída \\
\hline $\begin{array}{c}\text { Pieh-Holder KL. } \\
\text { (22) }\end{array}$ & 2013 & EE. UU. & $\mathrm{RC}$ & 31 & $2.6 \times 1.9$ & $\begin{array}{l}\text { No } \\
\text { informa }\end{array}$ & LMD & Embarazo & Biopsia & Tejido lactacional & Benigno & Escisión local & $*$ \\
\hline $\begin{array}{l}\text { Konstantinova A } \\
\text { et al.(70) }\end{array}$ & 2013 & $\begin{array}{l}\text { República } \\
\text { Checa }\end{array}$ & $\mathrm{RC}$ & 53 & 1.5 & $\begin{array}{l}\text { No } \\
\text { informa }\end{array}$ & LMD & Postmenopausia & $*$ & $\begin{array}{l}\text { Tejido mamario } \\
\text { quístico }\end{array}$ & Benigno & Escisión local & $\begin{array}{l}50 / \text { sin } \\
\text { recaída }\end{array}$ \\
\hline \multirow[t]{3}{*}{$\begin{array}{c}\text { Özbudak IH et } \\
\text { al (60) }\end{array}$} & 2013 & Turquía & $\mathrm{RC}$ & 43 & $4 \times 3$ & $\begin{array}{l}\text { No } \\
\text { informa }\end{array}$ & LMI & Edad fértil & $*$ & $\begin{array}{c}\text { Tumor Phyllodes } \\
\text { Benigno }\end{array}$ & Benigno & Escisión local & $*$ \\
\hline & 2013 & & $\mathrm{RC}$ & 50 & $3 \times 2$ & $\begin{array}{l}\text { No } \\
\text { informa }\end{array}$ & LMD & Edad fértil & $*$ & $\begin{array}{c}\text { Tumor Phyllodes } \\
\text { Benigno }\end{array}$ & Benigno & Escisión local & $*$ \\
\hline & 2013 & & $\mathrm{RC}$ & 78 & $*$ & $\begin{array}{l}\text { No } \\
\text { informa }\end{array}$ & LMiD & Postmenopausia & $\begin{array}{l}\text { Inmunohistoquí- } \\
\text { mica }\end{array}$ & $\begin{array}{l}\text { ADC Infiltrante } \\
\text { mamario }\end{array}$ & Maligno & $\begin{array}{l}\text { Escisión+ L+ } \\
\text { QT+ RT+HT }\end{array}$ & $*$ \\
\hline $\begin{array}{c}\text { Hassan R et al. } \\
\text { (53) }\end{array}$ & 2013 & Reino Unido & $\mathrm{PO}$ & 46 & $2 \times 2$ & $*$ & Clítoris & Edad fértil & $*$ & Fibroadenoma & Benigno & Escisión local & $*$ \\
\hline $\begin{array}{c}\text { McMaster J et } \\
\text { al (23) }\end{array}$ & 2013 & EE. UU. & $\mathrm{RC}$ & 60 & $2 \times 2$ & $\begin{array}{l}\text { No } \\
\text { informa }\end{array}$ & LMI & Postmenopausia & $\begin{array}{c}\text { Biopsia, Tac } \\
\text { de abdomen y } \\
\text { pelvis, Marcadores } \\
\text { tumorales Inmu- } \\
\text { nohistoquímica }\end{array}$ & ADC mamario & Maligno & Escisión local + RT & $*$ \\
\hline $\begin{array}{l}\text { Lev-Cohain N et } \\
\text { al. (24) }\end{array}$ & 2013 & EE. UU. & $\mathrm{RC}$ & 20 & $7 \times 5$ & $\begin{array}{l}\text { No } \\
\text { informa }\end{array}$ & LMD & Postparto & RM pelvis & Fibroadenoma & Benigno & Escisión local & $*$ \\
\hline $\begin{array}{l}\text { Anunobi CC et } \\
\text { al. (105) }\end{array}$ & 2013 & Nigeria & $\mathrm{RC}$ & 26 & $3 \times 3$ & $\begin{array}{l}\text { No } \\
\text { informa }\end{array}$ & LMD & Embarazo & $\begin{array}{l}\text { Inmunohistoquí- } \\
\text { mica }\end{array}$ & $\begin{array}{l}\text { Adenoma } \\
\text { lactógeno }\end{array}$ & Benigno & Escisión local & $*$ \\
\hline $\begin{array}{l}\text { Godoy-Gijón E et } \\
\text { al.(72) }\end{array}$ & 2012 & España & $\mathrm{RC}$ & 24 & $4 \times 2$ & $\begin{array}{c}\text { No } \\
\text { informa }\end{array}$ & LMI & Edad fértil & $*$ & $\begin{array}{c}\text { Tejido mamario } \\
\text { sano }\end{array}$ & Benigno & Escisión local & $2 /$ sin recaída \\
\hline $\begin{array}{l}\text { Dhaoui A et al. } \\
\text { (106) }\end{array}$ & 2012 & Túnez & $\mathrm{RC}$ & 28 & $3 \times 3$ & $\begin{array}{l}\text { No } \\
\text { informa }\end{array}$ & Vulva & Lactancia & $*$ & $\begin{array}{l}\text { Adenoma } \\
\text { lactógeno }\end{array}$ & Benigno & Escisión local & $*$ \\
\hline $\begin{array}{c}\text { Naseer MA et al. } \\
\text { (104) }\end{array}$ & 2011 & Baréin & $\mathrm{RC}$ & 57 & $1.7 \times 0.8$ & $\begin{array}{c}\text { No } \\
\text { informa }\end{array}$ & LMD & Postmenopausia & $\begin{array}{c}\text { Tac abdomen y } \\
\text { pelvis, Marcadores } \\
\text { tumorales Biopsia, } \\
\text { Inmunohistoquí- } \\
\text { mica }\end{array}$ & Ca. ductal invasivo & Maligno & $\begin{array}{c}\text { Escisión+ L+ QT } \\
+\mathrm{RT}\end{array}$ & $*$ \\
\hline Zhang et al. (51) & 2011 & China & $\mathrm{RC}$ & 18 & $30 \times 40$ & $\begin{array}{l}\text { No } \\
\text { informa }\end{array}$ & LMI & Edad fértil & $\begin{array}{l}\text { Inmunohistoquí- } \\
\text { mica }\end{array}$ & Fibroadenoma & Benigno & Vulvectomía parcial & $\begin{array}{l}10 / \sin \\
\text { recaída }\end{array}$ \\
\hline $\begin{array}{l}\text { Hanief MR et } \\
\text { al. (54) }\end{array}$ & 2011 & Reino Unido & $\mathrm{RC}$ & 40 & $3.5 \times 4.5$ & $\begin{array}{l}\text { No } \\
\text { informa }\end{array}$ & Periné & Edad fértil & Ecografía & $\begin{array}{c}\text { Tejido mamario } \\
\text { sano }\end{array}$ & Benigno & Escisión local & $*$ \\
\hline Lee ES et al. (82) & 2011 & $\begin{array}{l}\text { Corea del } \\
\text { Sur }\end{array}$ & $\mathrm{RC}$ & 29 & $\begin{array}{c}(3-2-2-1 y \\
4-1)\end{array}$ & $\begin{array}{l}\text { No } \\
\text { informa }\end{array}$ & $\begin{array}{l}\text { Múltiple } \\
\text { (LMD y } \\
\text { LMI) }\end{array}$ & Embarazo & $\begin{array}{c}\text { Ecografía, Inmu- } \\
\text { nohistoquímica }\end{array}$ & $\begin{array}{l}\text { Adenoma } \\
\text { lactógeno }\end{array}$ & Benigno & Escisión local & $*$ \\
\hline
\end{tabular}

Continuación Tabla 1 


\begin{tabular}{|c|c|c|c|c|c|c|c|c|c|c|c|c|c|}
\hline$\stackrel{\grave{3}}{3}$ & ㅇํㄴ & 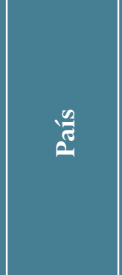 & $\begin{array}{l}\frac{0}{0} \\
\frac{0}{0} \\
\frac{0}{0}\end{array}$ & 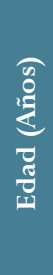 & 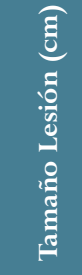 & ฮే & $\begin{array}{l}\frac{0}{0} \\
\frac{0}{8} \\
.0 \\
\frac{8}{3}\end{array}$ & 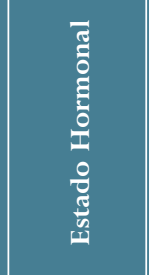 & 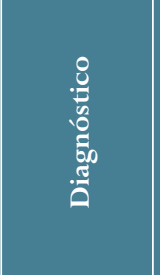 & 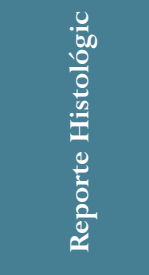 & 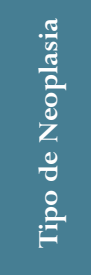 & 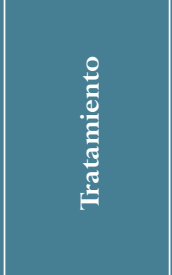 & 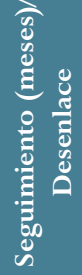 \\
\hline $\begin{array}{l}\text { Scarabin C et } \\
\text { al. (91) }\end{array}$ & 2010 & Francia & $\mathrm{RC}$ & 27 & $5-10$ & $\begin{array}{c}\text { No } \\
\text { informa }\end{array}$ & LMI & Embarazo & $*$ & $\begin{array}{l}\text { Adenoma } \\
\text { lactógeno }\end{array}$ & Benigno & Escisión local & $*$ \\
\hline $\begin{array}{l}\text { Mahajan } \mathrm{N} \text { et } \\
\text { al.(76) }\end{array}$ & 2010 & India & $\mathrm{RC}$ & 40 & $2 \times 1$ & $\begin{array}{l}\text { No } \\
\text { informa }\end{array}$ & LMD & Edad fértil & $*$ & Fibroadenoma & Benigno & Escisión local & $*$ \\
\hline $\begin{array}{l}\text { Mannan AA et } \\
\text { al. (88) }\end{array}$ & 2010 & Kuwait & $\mathrm{RC}$ & 18 & $5 \times 3$ & $\begin{array}{c}\text { No } \\
\text { informa }\end{array}$ & LMI & Edad fértil & $\begin{array}{l}\text { Inmunohistoquí- } \\
\text { mica }\end{array}$ & $\begin{array}{c}\text { Tumor Phyllodes } \\
\text { Benigno }\end{array}$ & Benigno & Escisión local & $\begin{array}{l}12 / \text { sin } \\
\text { recaída }\end{array}$ \\
\hline Mak CT. (25) & 2009 & EE. UU. & RC y RL & 17 & $*$ & Con pezón & LMD & Edad fértil & Biopsia & $\begin{array}{c}\text { Tejido mamario } \\
\text { sano }\end{array}$ & Benigno & Escisión local & $*$ \\
\hline Hong $\underset{(83)}{J H}$ et al. & 2009 & Corea del sur & $\mathrm{RC}$ & 18 & $5 \times 4$ & Sin pezón & LMI & Edad fértil & Ecografía & $\begin{array}{c}\text { Tejido mamario } \\
\text { sano }\end{array}$ & Benigno & Escisión local & $*$ \\
\hline $\begin{array}{c}\text { Sundaram S.S } \\
\text { (55) }\end{array}$ & 2009 & Reino Unido & $\mathrm{RC}$ & 37 & 1 & $\begin{array}{c}\text { No } \\
\text { informa }\end{array}$ & Clítoris & Edad fértil & Biopsia & $\begin{array}{c}\text { Tejido mamario } \\
\text { sano }\end{array}$ & Benigno & Escisión local & $*$ \\
\hline $\begin{array}{l}\text { Cantú de Leon D } \\
\text { et al. (101) }\end{array}$ & 2009 & México & $\mathrm{RC}$ & 18 & $12 \times 5$ & $\begin{array}{c}\text { No } \\
\text { informa }\end{array}$ & LMD & Edad fértil & $\begin{array}{l}\text { Biopsia por } \\
\text { aspiración, TAC } \\
\text { de pelvis }\end{array}$ & Fibroadenoma & Benigno & Escisión local & $\begin{array}{l}17 / \text { sin } \\
\text { recaída }\end{array}$ \\
\hline $\begin{array}{c}\text { Lucas EW et al. } \\
\text { (26) }\end{array}$ & 2009 & EE. UU. & $\mathrm{RC}$ & $*$ & $2 \times 3$ & $\begin{array}{l}\text { No infor- } \\
\text { ma (no se } \\
\text { consideró } \\
\mathrm{dx} \text { ) }\end{array}$ & LMD & $*$ & $*$ & Fibroadenoma & Benigno & Escisión local & $*$ \\
\hline $\begin{array}{c}\text { Bambao C et } \\
\text { al. (79) }\end{array}$ & 2008 & Canadá & $\mathrm{RC}$ & 45 & $0.4 \times 0.4$ & $\begin{array}{c}\text { No } \\
\text { informa }\end{array}$ & SID & Edad fértil & $\begin{array}{l}\text { Biopsia, Inmuno- } \\
\text { histoquímica }\end{array}$ & $\mathrm{HDB}$ & Benigno & Escisión local & $*$ \\
\hline $\begin{array}{l}\text { Shah SS et al. } \\
\text { (27) }\end{array}$ & 2008 & EE. UU. & $\mathrm{RC}$ & 92 & 2 & $\begin{array}{c}\text { No } \\
\text { informa }\end{array}$ & LMD & Postmenopausia & $\begin{array}{l}\text { Inmunohisto- } \\
\text { química }\end{array}$ & $\begin{array}{l}\text { ADC In situ } \\
\text { mamario }\end{array}$ & Maligno & Escisión local & $\begin{array}{l}15 / \text { sin } \\
\text { recaída }\end{array}$ \\
\hline & 2008 & & $\mathrm{RC}$ & 82 & 1 & $\begin{array}{c}\text { No } \\
\text { informa }\end{array}$ & LMiD & Postmenopausia & $\begin{array}{l}\text { Inmunohistoquí- } \\
\text { mica }\end{array}$ & $\begin{array}{l}\text { ADC In situ } \\
\text { mamario }\end{array}$ & Maligno & Escisión local & $\begin{array}{l}32 / \text { sin } \\
\text { recaída }\end{array}$ \\
\hline Vazmitel M (71) & 2008 & $\begin{array}{l}\text { República } \\
\text { Checa }\end{array}$ & $\mathrm{RC}$ & 30 & 0.5 & $\begin{array}{c}\text { No } \\
\text { informa }\end{array}$ & Vulva & Edad fértil & $\begin{array}{l}\text { Inmunohistoquí- } \\
\text { mica }\end{array}$ & $\begin{array}{l}\text { Hidradenoma } \\
\text { Papilifero }\end{array}$ & Benigno & Escisión local & $*$ \\
\hline $\begin{array}{c}\text { Carter JE et al. } \\
\text { (28) }\end{array}$ & 2008 & EE. UU. & $\mathrm{RC}$ & 45 & $5 \times 3.5$ & $\begin{array}{c}\text { No } \\
\text { informa }\end{array}$ & LMI & Postmenopausia & * & Fibroadenoma & Benigno & Escisión local & $*$ \\
\hline $\begin{array}{l}\text { Dordević M et } \\
\text { al. (99) }\end{array}$ & 2008 & Serbia & $\mathrm{RC}$ & 27 & $5 \times 3$ & $\begin{array}{c}\text { No } \\
\text { informa }\end{array}$ & LMI & Edad fértil & $\begin{array}{c}\text { Inmunohistoquí- } \\
\text { mica }\end{array}$ & $\begin{array}{c}\text { Tejido mamario } \\
\text { sano }\end{array}$ & Benigno & Escisión local & * \\
\hline $\begin{array}{c}\text { Duvvur S et al. } \\
\text { (56) }\end{array}$ & 2007 & Reino Unido & $\mathrm{RC}$ & 41 & $1 \times 1$ & Sin pezón & Vulva & Edad fértil & $*$ & $\begin{array}{c}\text { Tejido mamario } \\
\text { sano }\end{array}$ & Benigno & Escisión local & $*$ \\
\hline Giger OT. (96) & 2007 & Suiza & $\mathrm{RC}$ & 49 & $3.7 \times 3$ & $\begin{array}{c}\text { No } \\
\text { informa }\end{array}$ & LMD & Menopausia & $\begin{array}{c}\text { Inmunohistoquí- } \\
\text { mica }\end{array}$ & $\begin{array}{l}\text { Phyllodes Bor- } \\
\text { derline }\end{array}$ & Benigno & Escisión local & $*$ \\
\hline England E. (57) & 2007 & Reino Unido & $\mathrm{RC}$ & 45 & $1.5 \times 0.5$ & $\begin{array}{c}\text { No } \\
\text { informa }\end{array}$ & LMiI & Postmenopausia & $*$ & $\begin{array}{c}\text { Tejido mamario } \\
\text { sano }\end{array}$ & Benigno & Escisión local & $*$ \\
\hline $\begin{array}{c}\text { Kazakov DV et } \\
\text { al. (45) }\end{array}$ & 2006 & Rusia & $\mathrm{RC}$ & 64 & 2 & $\begin{array}{c}\text { No } \\
\text { informa }\end{array}$ & Periné & Postmenopausia & $\begin{array}{c}\text { Inmunohistoquí- } \\
\text { mica }\end{array}$ & $\mathrm{HDB}$ & Benigno & Escisión local & $\begin{array}{l}66 / \sin \\
\text { recaída }\end{array}$ \\
\hline Intra M et al. (63) & 2006 & Italia & RC y RL & 53 & 2 & $\begin{array}{c}\text { No } \\
\text { informa }\end{array}$ & LMI & Postmenopausia & $\begin{array}{l}\text { Biopsia, Inmu- } \\
\text { nohistoquímica, } \\
\text { Marcadores }\end{array}$ & ADC mamario & Maligno & $\begin{array}{c}\text { Hemivulvectomia } \\
\text { izquierda + BGC } \\
+ \text { HT }\end{array}$ & 20/viva \\
\hline $\begin{array}{l}\text { Fracchioli S et } \\
\text { al. (64) }\end{array}$ & 2006 & Italia & RC y RL & 57 & 1 & $\begin{array}{c}\text { No } \\
\text { informa }\end{array}$ & LMI & Postmenopausia & $\begin{array}{l}\text { Inmunohistoquí- } \\
\text { mica, Marcadores } \\
\text { tumorales }\end{array}$ & ADC mamario & Maligno & $\begin{array}{c}\text { Vulvectomía + L+ } \\
\text { QT+RT }\end{array}$ & 36/viva \\
\hline
\end{tabular}

Continuación Tabla 1 


\begin{tabular}{|c|c|c|c|c|c|c|c|c|c|c|c|c|c|}
\hline$\stackrel{\grave{3}}{\stackrel{2}{Z}}$ & 送 & 气ै & 를 & 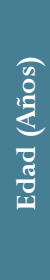 & 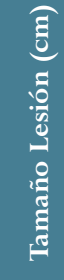 & อี & $\begin{array}{l}\frac{\Xi}{0} \\
\frac{0}{0} \\
.07 \\
\frac{0}{3}\end{array}$ & 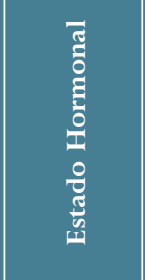 & 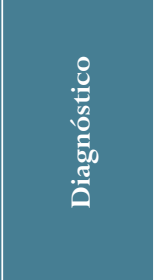 & 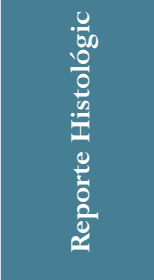 & 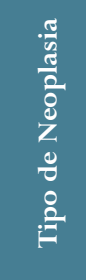 & 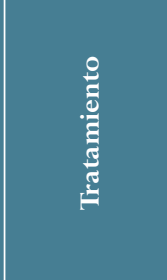 & 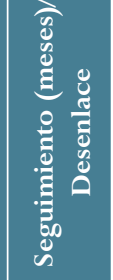 \\
\hline $\begin{array}{l}\text { Bardsley M et } \\
\text { al. (67) }\end{array}$ & 2004 & Australia & $\mathrm{RC}$ & 31 & $7 \times 4$ & $\begin{array}{c}\text { No } \\
\text { informa }\end{array}$ & Vulva & Postparto & $*$ & $\begin{array}{c}\text { Tejido mamario } \\
\text { sano }\end{array}$ & Benigno & Escisión local & 4/sin recaída \\
\hline $\begin{array}{l}\text { Lopes G et al. } \\
\text { (29) }\end{array}$ & 2006 & EE. UU. & $\mathrm{RC}$ & 44 & 2 & $\begin{array}{c}\text { No } \\
\text { informa }\end{array}$ & LMI & Edad fértil & $\begin{array}{l}\text { Biopsia, inmuno- } \\
\text { histoquímica }\end{array}$ & ADC mamario & Maligno & $\begin{array}{c}\text { Vulvectomía radical } \\
\text { parcial + L+ } \\
\text { QT + RT + HT }\end{array}$ & $*$ \\
\hline Ohira S et al. (81) & 2004 & Japón & RC y RL & 82 & $7 \times 1.5$ & $\begin{array}{c}\text { No } \\
\text { informa }\end{array}$ & LMI & Postmenopausia & $\begin{array}{l}\text { Biopsia, marca- } \\
\text { dores tumorales, } \\
\text { Inmunohistoquí- } \\
\text { mica }\end{array}$ & ADC mamario & Maligno & Escisión +L & 20/viva \\
\hline $\begin{array}{l}\text { Baykal C et al. } \\
\text { (61) }\end{array}$ & 2004 & Turquía & RC y RL & 25 & 1 & $\begin{array}{c}\text { No } \\
\text { informa }\end{array}$ & LMI & Embarazo & $\begin{array}{l}\text { Inmunohistoquí- } \\
\text { mica }\end{array}$ & TMF & Benigno & Escisión local & $*$ \\
\hline Yin C et al. (30) & 2003 & EE. UU. & $\mathrm{RC}$ & 84 & $5 \times 3$ & $\begin{array}{c}\text { No } \\
\text { informa }\end{array}$ & Pubis & Postmenopausia & $\begin{array}{l}\text { Inmunohistoquí- } \\
\text { mica }\end{array}$ & ADC mucinoso & Maligno & Vulvectomía +L & 9/sin recaída \\
\hline Piura B. (84) & 2002 & Israel & $\mathrm{RC}$ & 69 & $3 \times 3$ & $\begin{array}{c}\text { No } \\
\text { informa }\end{array}$ & LMI & Postmenopausia & $\begin{array}{l}\text { Inmunohistoquí- } \\
\text { mica }\end{array}$ & ADC mamario & Maligno & $\begin{array}{c}\text { Vulvectomía radical } \\
\text { +L+ QT + RT + } \\
\text { HT }\end{array}$ & $\begin{array}{l}12 / \sin \\
\text { recaída }\end{array}$ \\
\hline Baisre A. (31) & 2002 & EE. UU. & $\mathrm{RC}$ & 29 & 1.3 & $*$ & Vulva & Edad fértil & $*$ & Fibroadenoma & Benigno & Escisión local & $*$ \\
\hline & 2002 & & $\mathrm{RC}$ & 42 & 1.5 & $*$ & Vulva & Edad fértil & $*$ & Fibroadenoma & Benigno & Escisión local & * \\
\hline $\begin{array}{c}\text { Chung-Park M et } \\
\text { al. (32) }\end{array}$ & 2002 & EE. UU. & $\mathrm{RC}$ & 47 & 2 & $\begin{array}{c}\text { No } \\
\text { informa }\end{array}$ & LMiD & Postmenopausia & Biopsia & ADC mucinoso & Maligno & $\begin{array}{c}\text { Vulvectomía radical } \\
\text { anterior }\end{array}$ & $\begin{array}{l}36 / \text { sin } \\
\text { recaída }\end{array}$ \\
\hline $\begin{array}{c}\text { Kuan SF et al. } \\
\text { (33) }\end{array}$ & 2001 & EE. UU. & $\mathrm{RC}$ & 66 & $*$ & $\begin{array}{l}\text { No } \\
\text { informa }\end{array}$ & Vulva & Postmenopausia & $\begin{array}{l}\text { Inmunohistoquí- } \\
\text { mica }\end{array}$ & $\begin{array}{l}\text { Enf. Paget Extra- } \\
\text { mamaria }\end{array}$ & Maligno & Escisión local & $*$ \\
\hline & 2001 & & $\mathrm{RC}$ & 72 & $*$ & $\begin{array}{l}\text { No } \\
\text { informa }\end{array}$ & Vulva & Postmenopausia & $\begin{array}{l}\text { Inmunohistoquí- } \\
\text { mica }\end{array}$ & $\begin{array}{l}\text { Enf. Paget Extra- } \\
\text { mamaria }\end{array}$ & Maligno & Escisión local & $*$ \\
\hline & 2001 & & $\mathrm{RC}$ & 60 & * & $\begin{array}{l}\text { No } \\
\text { informa }\end{array}$ & Vulva & Postmenopausia & $\begin{array}{l}\text { Inmunohistoquí- } \\
\text { mica }\end{array}$ & $\begin{array}{c}\text { Enf. Paget Extra- } \\
\text { mamaria }\end{array}$ & Maligno & Escisión local & $*$ \\
\hline & 2001 & & $\mathrm{RC}$ & 80 & * & $\begin{array}{c}\text { No } \\
\text { informa }\end{array}$ & Vulva & Postmenopausia & $\begin{array}{l}\text { Inmunohistoquí- } \\
\text { mica }\end{array}$ & $\begin{array}{l}\text { Enf. Paget Extra- } \\
\text { mamaria }\end{array}$ & Maligno & Escisión local & $*$ \\
\hline & 2001 & & $\mathrm{RC}$ & 77 & $*$ & $\begin{array}{c}\text { No } \\
\text { informa }\end{array}$ & Vulva & Postmenopausia & $\begin{array}{l}\text { Inmunohistoquí- } \\
\text { mica }\end{array}$ & $\begin{array}{l}\text { Enf. Paget Extra- } \\
\text { mamaria }\end{array}$ & Maligno & Escisión local & $*$ \\
\hline & 2001 & & $\mathrm{RC}$ & 72 & $*$ & $\begin{array}{c}\text { No } \\
\text { informa }\end{array}$ & Vulva & Postmenopausia & $\begin{array}{l}\text { Inmunohistoquí- } \\
\text { mica }\end{array}$ & $\begin{array}{l}\text { Enf. Paget Extra- } \\
\text { mamaria }\end{array}$ & Maligno & Escisión local & $*$ \\
\hline & 2001 & & $\mathrm{RC}$ & 65 & $*$ & $\begin{array}{c}\text { No } \\
\text { informa }\end{array}$ & Vulva & Postmenopausia & $\begin{array}{l}\text { Inmunohistoquí- } \\
\text { mica }\end{array}$ & $\begin{array}{l}\text { Enf. Paget Extra- } \\
\text { mamaria }\end{array}$ & Maligno & Escisión local & $*$ \\
\hline & 2001 & & $\mathrm{RC}$ & 70 & * & $\begin{array}{c}\text { No } \\
\text { informa }\end{array}$ & Vulva & Postmenopausia & $\begin{array}{c}\text { Inmunohistoquí- } \\
\text { mica }\end{array}$ & $\begin{array}{l}\text { Enf. Paget Extra- } \\
\text { mamaria }\end{array}$ & Maligno & Escisión local & $*$ \\
\hline $\begin{array}{l}\text { Chulia MT et } \\
\text { al. (73) }\end{array}$ & 2001 & España & $\mathrm{RC}$ & 34 & $6 \times 4$ & $\begin{array}{c}\text { No } \\
\text { informa }\end{array}$ & LMI & Edad fértil & $\begin{array}{l}\text { Inmunohistoquí- } \\
\text { mica }\end{array}$ & $\begin{array}{c}\text { Tumor Phyllodes } \\
\text { Benigno }\end{array}$ & Benigno & Escisión local & $\begin{array}{l}18 / \text { Sin } \\
\text { recaída }\end{array}$ \\
\hline Neumann I. (90) & 2000 & Alemania & $\mathrm{RC}$ & 60 & * & $\begin{array}{c}\text { No } \\
\text { informa }\end{array}$ & LMD & Postmenopausia & $\begin{array}{l}\text { Marcadores } \\
\text { tumorales }\end{array}$ & $\begin{array}{l}\text { Ca. Mamario } \\
\text { lobular }\end{array}$ & Maligno & $\begin{array}{c}\text { Escisión + } \\
+\mathrm{QT}+\mathrm{RT}+\mathrm{HT}\end{array}$ & $\begin{array}{l}\text { 20/sin } \\
\text { recaída }\end{array}$ \\
\hline Gorisek B. (98) & 2000 & Eslovenia & $\mathrm{RC}$ & 81 & $2 \times 3$ & $*$ & LMI & Postmenopausia & $*$ & Ca. Ductal & Maligno & Escisión+ HT & $\begin{array}{l}\text { 19/sin } \\
\text { recaída }\end{array}$ \\
\hline
\end{tabular}

Continuación Tabla 1 


\begin{tabular}{|c|c|c|c|c|c|c|c|c|c|c|c|c|c|}
\hline$\stackrel{\grave{2}}{\stackrel{2}{Z}}$ & 递 & 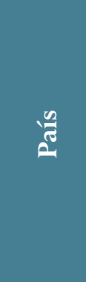 & 율 & 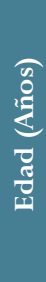 & 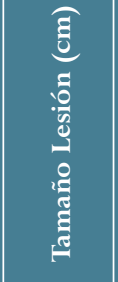 & ฮే & 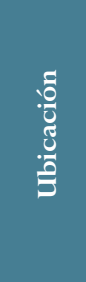 & 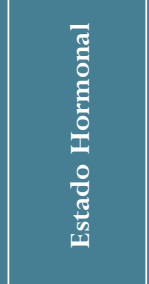 & 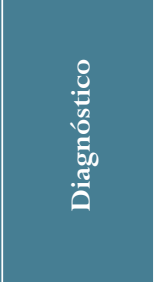 & 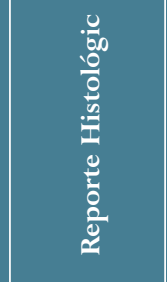 & 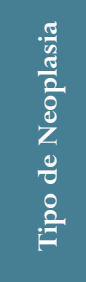 & 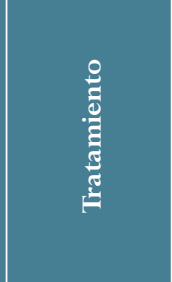 & 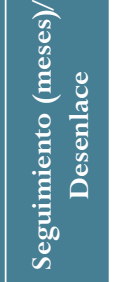 \\
\hline Irvin WP. (34) & 1999 & EE. UU. & RC y RL & 64 & $3 \times 3$ & $\begin{array}{c}\text { No } \\
\text { informa }\end{array}$ & Pubis & Postmenopausia & $\begin{array}{l}\text { Biopsia, marca- } \\
\text { dores tumorales, } \\
\text { Inmunohistoquí- } \\
\text { mica }\end{array}$ & ADC mamario & Maligno & $\begin{array}{c}\text { Escisión+ L + QT } \\
+ \text { RT + HT }\end{array}$ & 4/sin recaída \\
\hline Kapila K. (89) & 1998 & Kuwait & $\mathrm{CE}$ & 30 & $1 \times 2$ & $\begin{array}{c}\text { No } \\
\text { informa }\end{array}$ & Múltiple & Embarazo & $\begin{array}{l}\text { Biopsia por } \\
\text { aspiración }\end{array}$ & $\begin{array}{c}\text { Tejido mamario } \\
\text { sano }\end{array}$ & Benigno & Escisión local & $*$ \\
\hline Tresserra F. (74) & 1998 & España & $\mathrm{RC}$ & 39 & $1.4 \times 2$ & $\begin{array}{c}\text { No } \\
\text { informa }\end{array}$ & LMI & Edad fértil & $\begin{array}{l}\text { Inmunohistoquí- } \\
\text { mica }\end{array}$ & $\begin{array}{c}\text { Tumor Phyllodes } \\
\text { Benigno }\end{array}$ & Benigno & Escisión local & $\begin{array}{l}18 / \text { Sin } \\
\text { recaída }\end{array}$ \\
\hline & 1998 & & $\mathrm{RC}$ & 17 & $0.7-1.6$ & $\begin{array}{c}\text { No } \\
\text { informa }\end{array}$ & Múltiple & Edad fértil & $\begin{array}{l}\text { Inmunohistoquí- } \\
\text { mica }\end{array}$ & $\begin{array}{c}\text { Tumor Phyllodes } \\
\text { Benigno }\end{array}$ & Benigno & Escisión local & $\begin{array}{l}\text { */Sin } \\
\text { recaída }\end{array}$ \\
\hline Higgins CM. (68) & 1997 & Australia & $\mathrm{RC}$ & 37 & 5 & $\begin{array}{c}\text { No } \\
\text { informa }\end{array}$ & LMI & Edad fértil & $\begin{array}{l}\text { Inmunohistoquí- } \\
\text { mica }\end{array}$ & $\begin{array}{c}\text { Fibroadenoma } \\
\text { papilar }\end{array}$ & Benigno & Escisión local & $*$ \\
\hline Xanos ET. (35) & 1997 & EE. UU. & $\mathrm{RC}$ & 31 & $4 \times 5$ & $\begin{array}{l}\text { No } \\
\text { informa }\end{array}$ & Múltiple & Embarazo & Ecografía & Fibroadenoma & Benigno & Escisión local & $*$ \\
\hline $\begin{array}{l}\text { Kennedy DA et } \\
\text { al. (36) }\end{array}$ & 1997 & EE. UU. & $\mathrm{RC}$ & 71 & $5 \times 2$ & $\begin{array}{c}\text { No } \\
\text { informa }\end{array}$ & LMI & Postmenopausia & $\begin{array}{l}\text { Biopsia, Inmuno- } \\
\text { histoquímica }\end{array}$ & Ca. ductal invasivo & Maligno & $\begin{array}{l}\text { Vulvectomía radical } \\
+\mathrm{L}+\mathrm{QT}+\mathrm{RT}\end{array}$ & $15 /$ viva \\
\hline Kais M. (85) & 1995 & Israel & $\mathrm{RC}$ & 34 & $4.5 \times 3.5 \times 3$ & $*$ & Vulva & Edad fértil & $\begin{array}{l}\text { Inmunohistoquí- } \\
\text { mica }\end{array}$ & $\begin{array}{c}\text { Tumor Phyllodes } \\
\text { Benigno }\end{array}$ & Benigno & Escisión local & $3 /$ sin recaída \\
\hline Prasad KR. (77) & 1995 & India & $\mathrm{RC}$ & 30 & 4 & $*$ & Vulva & Edad fértil & $*$ & Fibroadenoma & Benigno & Escisión local & $*$ \\
\hline $\begin{array}{l}\text { Levin } M \text { et al. } \\
\text { (37) }\end{array}$ & 1995 & EE. UU. & $\mathrm{RC}$ & 62 & 2.5 & $\begin{array}{c}\text { No } \\
\text { informa }\end{array}$ & LMI & Postmenopausia & $\begin{array}{l}\text { Biopsia, Inmuno- } \\
\text { histoquímica }\end{array}$ & $\mathrm{ADC}$ mamario & Maligno & $\begin{array}{c}\text { Escisión + L+ } \\
\text { RT + HT }\end{array}$ & $\begin{array}{c}12 / \sin \\
\text { actividad }\end{array}$ \\
\hline $\begin{array}{c}\text { Bailey CL et al. } \\
\text { (38) }\end{array}$ & 1993 & EE. UU. & $\mathrm{RC}$ & 65 & $3 \mathrm{X} 2$ & $\begin{array}{c}\text { No } \\
\text { informa }\end{array}$ & LMD & Postmenopausia & $\begin{array}{l}\text { Inmunohistoquí- } \\
\text { mica }\end{array}$ & Ca. Ductal & Maligno & Escisión + HT & 12/viva \\
\hline $\begin{array}{l}\text { Thakhi A et al. } \\
\text { (39) }\end{array}$ & 1993 & EE. UU. & $\mathrm{RC}$ & 20 & $3 \times 4$ & $\begin{array}{c}\text { No } \\
\text { informa }\end{array}$ & Múltiple & Edad fértil & $\begin{array}{l}\text { Inmunohistoquí- } \\
\text { mica }\end{array}$ & $\begin{array}{c}\text { Tumor Phyllodes } \\
\text { Benigno }\end{array}$ & Benigno & Escisión local & 8/sin recaída \\
\hline $\begin{array}{l}\text { Di Bonito Let } \\
\text { al. (65) }\end{array}$ & 1992 & Italia & $\mathrm{RC}$ & 42 & 1.5 & $\begin{array}{c}\text { No } \\
\text { informa }\end{array}$ & LMD & Edad fértil & $\begin{array}{l}\text { Inmunohistoquí- } \\
\text { mica }\end{array}$ & ADC mamario & Maligno & $\begin{array}{l}\text { Vulvectomía radical } \\
\qquad+\mathrm{L}\end{array}$ & 4/viva \\
\hline $\begin{array}{c}\text { Rose PG et al. } \\
\quad(40)\end{array}$ & 1990 & EE. UU. & $\mathrm{RC}$ & 68 & $3.5 \times 3.5$ & $*$ & LMD & Postmenopausia & $\begin{array}{l}\text { Inmunohistoquí- } \\
\text { mica }\end{array}$ & Ca. Ductal & Maligno & $\begin{array}{c}\text { Escisión+ } \\
\text { RT+HT }\end{array}$ & $*$ \\
\hline $\begin{array}{l}\text { Simon KE et } \\
\text { al. (41) }\end{array}$ & 1988 & EE. UU. & $\mathrm{RC}$ & 60 & $2 \mathrm{X} 2$ & $\begin{array}{c}\text { No } \\
\text { informa }\end{array}$ & LMD & Postmenopausia & $\begin{array}{l}\text { Biopsia, Inmuno- } \\
\text { histoquímica }\end{array}$ & $\mathrm{ADC}$ mamario & Maligno & $\begin{array}{c}\text { Vulvectomía radical } \\
\text { + L+ QT+ } \\
\text { RT+HT }\end{array}$ & 27/fallecida \\
\hline $\begin{array}{l}\text { Reeves KO et } \\
\text { al. (42) }\end{array}$ & 1980 & EE. UU. & $\mathrm{RC}$ & 29 & $3 \times 4$ & $\begin{array}{l}\text { No } \\
\text { informa }\end{array}$ & Clítoris & Postparto & Biopsia & TMF & Benigno & Escisión local & $*$ \\
\hline $\begin{array}{l}\text { Guerry RL et } \\
\text { al. (43) }\end{array}$ & 1976 & EE. UU. & $\mathrm{RC}$ & 62 & 1.5 & $\begin{array}{c}\text { No } \\
\text { informa }\end{array}$ & LMI & Postmenopausia & Biopsia & Ca. ductal invasivo & Maligno & Escisión local & 24/fallecida \\
\hline
\end{tabular}

ADC: Adenocarcinoma; BGC: Biopsia de Ganglio Centinela; Ca: Carcinoma; CE: Carta editor; Enf: Enfermedad; ESGO: European Society of Gynaecological Oncology; EE. UU.: Estados Unidos; HDB: Hiperplasia Ductal Benigna; HAT: Histerectomía abdominal; HT: Hormonoterapia; IM: Imagen del mes; LMD: Labio mayor derecho; LMI: Labio mayor izquierdo; LMiI: Labio menor izquierdo; LMiD: Labio menor derecho. L: Linfadenectomía, PO: Presentación Oral; QT: Quimioterapia; RM: resonancia magnética; RT: Radioterapia; RC: Reporte caso; RL: Revisión literatura, SC: Serie de casos; SID: Surco interlabial derecho; SOB: salpingo-oforectomía bilateral; TEP: tomografía por emisión de positrones; TMF: Tejido mamario fibroquístico; NA: no aplica; * Sin información. 


\section{CONCLUSIONES}

El tejido mamario ectópico en vulva debe ser considerado como parte del diagnóstico diferencial de masas a nivel vulvar con diferente pronóstico en mujeres pre y posmenopáusicas. Se debe mejorar en la descripción de las lesiones, ya que en pocos estudios se describía presencia o no de pezón o areola. Se requieren más estudios para poder definir qué tratamiento consigue los mejores resultados en términos de recaída y supervivencia.

\section{REFERENCIAS}

1. Harris JR, Lippman ME, Morrow M, Osborne CK. Diseases of the breast. 2nd ed. Philadelphia, PA: Lippincott Williams \& Wilkins; 2000. 1 -14 p.

2. Velanovich V. Ectopic breast tissue, supernumerary breasts, and supernumerary nipples. South Med J. 1995;88(9):903-6. https://doi. org/10.1097/00007611-199509000-00002

3. Copeland MM, Geschickter CF. Diagnosis and treatment of premalignant lesions of the breast. Surg Clin North Am. 1950;30(6):1717-41. https://doi. org/10.1016/S0039-6109(16)33194-2

4. Mehregan AH. Supernumerary Nipple. A Histologic Study. J Cutan Pathol. 1981;8(2):96-104. https://doi. org/10.1111/j.1600-0560.1981.tb00992.x

5. DeFilippis EM, Arleo EK. The ABCs of accessory breast tissue: Basic information every radiologist should know. Am J Roentgenol. 2014;202(5):115762. https://doi.org/10.2214/AJR.13.10930

6. Moy L, Heller SL, Bailey L, D’Orsi C, DiFlorio RM, Green ED, et al. ACR Appropriateness Criteria () Palpable Breast Masses. J Am Coll Radiol. 2017;14(5):S203-24. https://doi.org/10.1016/j. jacr.2017.02.033

7. Kransdorf, Mark J. Murphey, Mark D. Wessell DE. Soft-Tissue Masses. ACR Appropriateness Criteria. 2017. p. 1-10. Disponible en: https://acsearch.acr. org/docs/69434/Narrative/

8. Lim HS, Kim SJ, Baek JM, Kim JW, Shin SS, Seon $\mathrm{HJ}$, et al. Sonographic findings of accessory breast tissue in axilla and related diseases. J Ultrasound Med. 2017;36(7):1469-78. https://doi.org/10.7863/ ultra.16.06056
9. Aydogan F, Baghaki S, Celik V, Kocael A, Gokcal F, Cetinkale O, et al. Surgical treatment of axillary accessory breasts. Am Surg. 2010;76(3):270-2. https:// doi.org/10.1177/000313481007600305

10. Salemis NS. Primary ectopic breast carcinoma in the axilla: A rare presentation and review of the literature. Breast Dis. 2021;40(2):109-14. https://doi. org/10.3233/BD-201027

11. Deaver, John B. McFarland, Joseph. Herman L. The Breast: Its Anomalies, Its Diseases, and Their Treatment. Company BS\&, editor. 1917. 724; p61-65 p.

12. Djordjevic M, Jovanovic B, Mitrovic S, Djordjevic G. Ectopic mammary tissue in vulva. Vojnosanit Pregl. 2008;65(5):407-9. https://doi.org/10.2298/ VSP0805407D

13. Van der Putte SCJ. Mammary-like Glands of the Vulva and Their Disorders. Int J Gynecol Pathol. 1994;13(2):150-60. https://doi. org/10.1097/00004347-199404000-00009

14. Butler B, Leath CA, Barnett JC. Primary invasive breast carcinoma arising in mammary-like glands of the vulva managed with excision and sentinel lymph node biopsy. Gynecol Oncol Reports. 2014;7(2014):7-9. https://doi.org/10.1016/j.gynor.2013.09.001

15. Manterola C, Asenjo-Lobos C, Otzen T. Jerarquización de la evidencia. Niveles de evidencia y grados de recomendación de uso actual. Rev Chil infectología. 2014;31(6):14. https://doi.org/10.4067/S071610182014000600011

16. Hernandez Lopez AL, Manandhar S, Dubow L. Pregnancy-unrelated fibroadenoma in ectopic breast tissue in the axilla and vulva: A case report. Case Reports Women's Heal. 2020;28:e00255. https://doi. org/10.1016/j.crwh.2020.e00255

17. Ananthula A, Lockwood B, Savage J, Malak S, Chen C, Makhoul I PA. Primary breast carcinoma of the vulva metastatic to lymph nodes and bones: A case report and literature review. Perm J. 2020;24:19.084. Disponible en: http://www.thepermanentejournal.org/ issues/2020/spring/7384-BreastCancer.html\# ref

18. De La Vega GA, Jean Qureshey E. Tejido mamario ectópico activo en vulva en paciente posparto. Reporte de un caso. Rev Perú Ginecol y Obstet. 2020;66(1):79_ 82. https://doi.org/10.31403/rpgo.v66i2236 
19. Mikhael S, Nilsson W, Patel K, Graf S. Ectopic Breast Tissue of the Vulva in a Postmenopausal Woman. Case Rep Obstet Gynecol. 2017;2017:1-2. https:/doi. org/10.1155/2017/7581750

20. Cripe J, Eskander R, Tewari K. Sentinel lymph node mapping of a breast cancer of the vulva: Case report and literature review. World J Clin Oncol. 2015;6(2):16. https://doi.org/10.5306/wjco.v6.i2.16

21. Wagner IJ, Damitz LA, Carey E, Zolnoun D. Bilateral Accessory Breast Tissue of the Vulva: A Case Report Introducing a Novel Labiaplasty Technique. Ann Plast Surg. 2013;70(5):549-52. https://doi.org/10.1097/ SAP.0b013e31827ead39

22. Pieh-Holder KL. Lactational Ectopic Breast Tissue of the Vulva: Case Report and Brief Historical Review. Breastfeed Med. 2013;8(2):223-5. https://doi. org/10.1089/bfm.2012.0128

23. McMaster J, Dua A, Dowdy SC. Primary Breast Adenocarcinoma in Ectopic Breast Tissue in the Vulva. Case Rep Obstet Gynecol. 2013;2013:1-3. https:// doi.org/10.1155/2013/721696

24. Lev-Cohain N, Kapur P, Pedrosa I. Vulvar Fibroadenoma with Lactational Changes in Ectopic Breast Tissue. Case Rep Obstet Gynecol. 2013;2013:1-4. https://doi.org/10.1155/2013/924902

25. Mak CT, Veras E, Loveless MB. Supernumerary Nipple Presenting as a Vulvar Mass in an Adolescent: Case Report and Literature Review. J Pediatr Adolesc Gynecol. 2009;22(4):e41-4. https://doi.org/10.1016/j. jpag.2008.03.001

26. Lucas EW, Branton P, Mecklenburg FE, Moawad GN. Ectopic Breast Fibroadenoma of the Vulva. Obstet Gynecol. 2009;114(2):460-2. https://doi.org/10.1097/ AOG.0b013e3181af672d

27. Shah SS, Adelson M, Mazur MT. Adenocarcinoma In Situ Arising in Vulvar Papillary Hidradenoma: Report of 2 Cases. Int J Gynecol Pathol. 2008;27(3):453-6. https://doi.org/10.1097/PGP.0b013e31815b8eee

28. Carter JE, Mizell KN, Tucker JA. Mammary-type fibroepithelial neoplasms of the vulva: a case report and review of the literature. J Cutan Pathol. 2008;35 (2):246-9. Disponible en: http://doi.wiley. com/10.1111/j.1600-0560.2007.00796.x

29. Lopes G, DeCesare T, Ghurani G, Vincek V, Jorda M, Glück S, et al. Primary Ectopic Breast Cancer Present- ing as a Vulvar Mass. Clin Breast Cancer. 2006;7(3):2789. https://doi.org/10.3816/CBC.2006.n.041

30. Yin C, Chapman J, Tawfik O. Invasive Mucinous (Colloid) Adenocarcinoma of Ectopic Breast Tissue in the Vulva: A Case Report. Breast J. 2003;9(2):113-5. https://doi.org/10.1046/j.1524-4741.2003.09213.x

31. Baisre A, Heller DS, Lee J, Zheng P. Fibroadenoma of the vulva. A report of two cases. J Reprod Med. 2002;47(11):949-51. Disponible en: http://www.ncbi. nlm.nih.gov/pubmed/12497689

32. Chung-Park M, Zheng Liu C, Giampoli EJ, Emery JD, Shalodi A. Mucinous adenocarcinoma of ectopic breast tissue of the vulva. Arch Pathol Lab Med. 2002;126(10):1216-8. https://doi.org/10.5858/2002126-1216-MAOEBT

33. Kuan SF, Montag AG, Hart J, Krausz T, Recant W. Differential expression of mucin genes in mammary and extramammary Paget's disease. Am J Surg Pathol. 2001;25(12):1469-77. https://doi. org/10.1097/00000478-200112000-00001

34. Irvin WP, Cathro HP, Grosh WW, Rice LW, Andersen WA. Primary breast carcinoma of the vulva: A case report and literature review. Gynecol Oncol. 1999;73(1):1559. https://doi.org/10.1006/gyno.1998.5269

35. Xanos ET, Kennedy DA, Grosen EA. Pregnancy-Related Fibroadenoma of Ectopic Breast Tissue in the Vulva. J Low Genit Tract Dis. 1997;1(3):182-4. https://doi. org/10.1097/00128360-199707000-00035

36. Kennedy DA, Hermina MS, Xanos ET, Schink JC, Hafez G. Infiltrating Ductal Carcinoma of the Vulva. Pathol - Res Pract. 1997;193(10):723-6. https://doi. org/10.1016/S0344-0338(97)80033-7

37. Levin M, Pakarakas RM, Chang HA, Maiman M, Goldberg SL. Primary Breast Carcinoma of the Vulva: A Case Report and Review of the Literature. Gynecol Oncol. 1995;56(3):448-51. https://doi.org/10.1006/ gyno. 1995.1080

38. Bailey CL, Sankey HZ, Donovan JT, Beith KA, Otis CN, Powell JL. Primary Breast Cancer of the Vulva. Gynecol Oncol. 1993;50(3):379-83. https://doi.org/10.1006/ gyno. 1993.1230

39. Tbakhi A, Cowan DF, Kumar D, Kyle D. Recurring Phyllodes Tumor in Aberrant Breast Tissue of the Vulva. Am J Surg Pathol. 1993;17(9):946-50. https://doi. org/10.1097/00000478-199309000-00013 
40. Rose PG, Roman LD, Reale FR, Tak WK, Hunter RE. Primary adenocarcinoma of the breast arising in the vulva. Obstet Gynecol. 1990;76(3 Pt 2):537-9. Disponible en: http://www.ncbi.nlm.nih. gov/pubmed/2199874

41. Simon KE, Dutcher JP, Runowicz CD, Wiernik PH. Adenocarcinoma arising in vulvar breast tissue. Cancer. 1988;62(10):2234-8. https://doi.org/10.1002/1097$0142(19881115) 62: 10<2234$ : : I D CNCR2820621027>3.0.CO;2-F

42. Reeves KO, Kaufman RH. Vulvar ectopic breast tissue mimicking periclitoral abscess. Am J Obstet Gynecol. 1980;137(4):509-11. https://doi.org/10.1016/00029378(80)91138-2

43. Guerry RL, Pratt-Thomas HR. Carcinoma of supernumerary breast of vulva with bilateral mammary cancer. Cancer. 1976;38(6):2570-4. https://doi. org/10.1002/1097-0142(197612)38:6<2570::AIDCNCR2820380650>3.0.CO;2-T

44. Kredentser AM, Kredentser DC. Adenocarcinoma of the Vulva Arising in Ectopic Breast Tissue: A Case Series and Literature Review. J Gynecol Surg. 2017;33(1):22_ 6. https://doi.org/10.1089/gyn.2016.0025

45. Kazakov D V., Belousova IE, Sima R, Michal M. Mammary type tubulolobular carcinoma of the anogenital area: report of a case of a unique tumor presumably originating in anogenital mammarylike glands. Am J Surg Pathol. 2006;30(9):1193-6. https://doi. org/10.1097/01.pas.0000213255.67693.e1

46. Konstantinova AM, Shelekhova K V., Imyanitov EN, Iyevleva A, Kacerovska D, Michal M, et al. Study of selected BRCA1, BRCA2, and PIK3CA mutations in benign and malignant lesions of anogenital mammarylike glands. Am J Dermatopathol. 2017;39(5):358-62. https://doi.org/10.1097/DAD.0000000000000725

47. Li G, Zhang Y, Ma H. Recurrent vulvar breast fibroadenoma: presentation of a rare clinical condition. J Int Med Res. 2019;47(3):1401-5. https://doi. org/10.1177/0300060519826771

48. Zhou M, Jin M, Wang L, Pan L-J. Pregnancy-associated gigantomastia recurrence and ectopic breast after reduction mammaplasty: A case report. Cancer Biomarkers. 2017;20(2):225-9. https://doi.org/10.3233/ CBM-160450
49. Arshad W, Kaur G. Peri-anal mammary-like gland adenoma-an unusual anal'skin tag'! Assoc Coloproctology Gt Britain Ireland. 2014;16 (Suppl.:41. Disponible en: https://click.endnote.com/viewer?doi $=10.1111 \% 2$ Fcod i.12644_2\&token $=$ Wzk3NDg3NSwiMTAuMTExMS9j b2RpLjEyNjQ0XzIiXQ.L1WUxsuGgLyH9YV46NHNllEiqeo

50. Zhang Z, Wang G, Jiang J, Zhang X, Kong B. Ectopic Mammary Tissue as a Vulvar Mass in a Lactating Woman. Breast J. 2014;20(1):91-2. https://doi.org/10.1111/ tbj. 12212

51. Zhang J, Chen Y, Wang K, Xi M, Yang K, Liu H. Prepubertal vulval fibroma with a coincidental ectopic breast fibroadenoma: Report of an unusual case with literature review. J Obstet Gynaecol Res. 2011;37(11):1720-5. https://doi.org/10.1111/j.1447-0756.2011.01580.x

52. Moulla A, Hunt L, Shaikh H, Datta S. Phyllodes Tumor in the Vulva. Breast J. 2017;23(4):476-8. https://doi. org/10.1111/tbj. 12767

53. Hassan R, Amalinei C, Riaz T. Ectopic mammary tissue of the vulva. BJOG-An Int J Obstet Gynaecol. 120, Suppl:p502-p502, 1p. Disponible en: https://eds-bebscohost-com.ezproxy.javeriana.edu.co/eds/detail/ detail? vid $=0 \&$ sid $=581 \mathrm{a9b} 43-70 \mathrm{e} 6-482 \mathrm{~b}-\mathrm{b} 5 \mathrm{~b} 5-\mathrm{f} 506$ 501c40c9\%40sessionmgr102\&bdata $=$ Jmxhbmc9ZX Mmc2l0ZT1lZHMtbGl2ZQ\%3D\%3D\#AN=000320 $781601515 \& \mathrm{db}=$ edswsc

54. Hanief M, Yongue G, Leff D, Lamb B, Karim S, Aref F, et al. A painful perineal lump: an unusual case of ectopic breast tissue. Ann R Coll Surg Engl. 2011;93(7):e147-8. https://doi.org/10.1308/147870811X602186

55. Sundaram SS, Gomez M, Harindra V. An unusual case of vulval lump: tumour of anogenital mammary-like glands. Int J STD AIDS. 2009;20(1):61-2. https://doi. org/10.1258/ijsa.2008.008241

56. Duvvur S, Sotres M, Lingam K, Srinivasan J. Ectopic breast tissue of the vulva. J Obstet Gynaecol (Lahore). 2007;27(5):530-1. https://doi. org/10.1080/01443610701467333

57. England E, Harms M, Zanetto U. Ectopic breast tissue presenting as a persistent vulval swelling in a primary care minor surgery clinic: A case report and review of the literature. Aust New Zeal J Obstet Gynaecol. 2007;47(5):424-5. https://doi.org/10.1111/j.1479-828X.2007.00770.x 
58. Kilitci A, Arioz O. Primary Benign Phyllodes Tumor of The Vulva: Case Report and Review of Literature. Eur J Breast Heal. 2019;15(3):196-9. https://doi. org/10.5152/ejbh.2019.4391

59. Baykal C, Dünder I, Turkmen IC, Ozyar E. An unusual case of mammary gland-like carcinoma of vulva: case report and review of literature. Eur J Gynaecol Oncol. 2015;36(3):333-4. Disponible en: http://www.ncbi.nlm. nih.gov/pubmed/26189264

60. Özbudak IH, Akkaya H, Akkaya B, Erdoğan G, Peşterelı HE, Karavelı FS. Phyllodes tumor of the vulva: report of two cases. Turk Patoloji Derg. 2013;29(1):73-6. https:// doi.org/10.5146/tjpath.2013.01153

61. Baykal C, Tulunay G, Usubutun A, Küçükali T, Ozer S, Demir OF. Fibrocystic Disease of Vulvar Ectopic Breast Tissue. Gynecol Obstet Invest. 2004;58(3):151-4. https://doi.org/10.1159/000079540

62. Del Vecchio V, Resta L, Mastromauro M, Loizzi V, Cicinelli E, Cormio G. Bone Metastases as Presenting Sign of Mammary-like Vulvar Adenocarcinoma. Open J Clin Med Case Rep. 2016;2(21):1-5. https://doi.org/10.26226/mo rressier.5770e29ed462b80290b4c91d

63. Intra M, Maggioni A, Sonzogni A, De Cicco C, Machado LS, Sagona A, et al. A rare association of synchronous intraductal carcinoma of the breast and invasive carcinoma of ectopic breast tissue of the vulva: case report and literature review. Int J Gynecol Cancer. 2006;16(S1):428-33. https://doi.org/10.1136/ijgc-00009577-20060200100080

64. Fracchioli S, Pupolo M, Rigault de la Longrais IA, Scozzafava M, Bogliatto F, ARISIO R, et al. Primary "breast-like" cancer of the vulva: a case report and critical review of the literature. Int J Gynecol Cancer. 2006;16(S1):423-8. https://doi.org/10.1111/j.1525-1438.2006.00364.x

65. Di Bonito L, Patriarca S, Falconieri G. Aggressive "Breast-like" Adenocarcinoma of Vulva. Pathol - Res Pract. 1992;188(1-2):211-4. https://doi.org/10.1016/ S0344-0338(11)81181-7

66. Al-Mansouri L, Poursoltan P, Simons M, Muljono A, Boyages J. Primary breast cancer of the vulva: A case report and literature review. J Obstet Gynaecol Res. 2018;44(12):2190-4. https://doi.org/10.1111/ jog. 13778
67. Bardsley M, Petterson C. Ectopic breast tissue presenting as a persistent vulval cyst. Aust New Zeal J Obstet Gynaecol. 2004;44(2):166-7. https://doi. org/10.1111/j.1479-828X.2004.00201.x

68. Higgins CM, Strutton GM. Papillary apocrine fibroadenoma of the vulva. J Cutan Pathol. 1997;24(4):256-60. https://doi.org/10.1111/j.1600-0560.1997.tb01591.x

69 Konstantinova AM, Kacerovska D, Michal M, Kazakov D V. A Composite Neoplastic Lesion of the Vulva With Mixed Features of Fibroadenoma and Hidradenoma Papilliferum Combined With Pseudoangiomatous Stromal Hyperplasia Containing Multinucleated Giant Cells. Am J Dermatopathol. 2014;36(10):e171-4. https://doi.org/10.1097/DAD.0b013e31828742e4

70. Konstantinova AM, Kacerovska D, Michal M, Kazakov D V. A tumoriform lesion of the vulva with features of mammary-type fibrocystic disease. Am J Dermatopathol. 2013;35(7):e124-7. https://doi.org/10.1097/ DAD.0b013e318284860c

71. Vazmitel M, Spagnolo D V, Nemcova J, Michal M, Kazakov D V. Hidradenoma Papilliferum With a Ductal Carcinoma In Situ Component: Case Report and Review of the Literature. Am J Dermatopathol. 2008;30(4):392-4. https://doi.org/10.1097/ DAD.0b013e31817c6a7d

72. Godoy-Gijón E, Yuste-Chaves M, Santos-Briz Á, Esteban-Velasco C, de Unamuno-Pérez P. Mama ectópica vulvar. Actas Dermosifiliogr. 2012;103(3):229-32. https://doi.org/10.1016/j.ad.2011.02.015

73. Chulia MT, Paya A, Niveiro M, Ceballos S, Aranda FI. Phyllodes tumor in ectopic breast tissue of the vulva. Int J Surg Pathol. 2001;9(1):81-3. https://doi. org/10.1177/106689690100900116

74. Tresserra F, Grases PJ, Izquierdo M, Cararach M, Fernandez-Cid A. Fibroadenoma Phyllodes Arising in Vulvar Supernumerary Breast Tissue. Int J Gynecol Pathol. 1998;17(2):171-3. https://doi. org/10.1097/00004347-199804000-00013

75. Kalyani R, Srinivas M V, Veda P. Vulval fibroadenoma - a report of two cases with review of literature. Int J Biomed Sci. 2014;10(2):143-5. Disponible en: http:// www.ncbi.nlm.nih.gov/pubmed/25018684

76. Mahajan Niraj N, Choudhrie L. Fibroadenoma of ectopic breast tissue in the vulva: a case report. J Ob- 
stet Gynecol India [Internet]. 2010;60(6):529-30. https://doi.org/10.1007/s13224-010-0055-7

77. Prasad KR, Kumari GS, Aruna CA, Durga K, Kameswari VR. Fibroadenoma of ectopic breast tissue in the vulva. A case report. Acta Cytol. 1995;39(4):7912. Disponible en: http://www.ncbi.nlm.nih.gov/ pubmed/7631557

78. Ardell S, Udayasankar V. Ectopic Breast Tissue in the Vulva in Pregnancy. J Obstet Gynaecol Canada. 2019;000 (000):1. https://doi.org/10.1016/j. jogc.2019.09.026

79. Bambao C, Rasty G, Bandarchi B, Shier M. Benign Ductal Hyperplasia and Adenosis of Mammary-Like Glands of the Vulva. J Low Genit Tract Dis. 2008;12(1):32-4. https://doi.org/10.1097/ LGT.0b013e31806bf02a

80. Ishigaki T, Toriumi Y, Nosaka R, Kudou R, Imawari Y, Kamio M, et al. Primary ectopic breast cancer of the vulva, treated with local excision of the vulva and sentinel lymph node biopsy: a case report. Surg Case Reports. 2017;3(1):69. https://doi.org/10.1186/ s40792-017-0343-x

81. Ohira S, Itoh K, Osada K, Oka K, Suzuki A, Osada R, et al. Vulvar Paget's disease with underlying adenocarcinoma simulating breast carcinoma: case report and review of the literature. Int J Gynecol Cancer. 2004;14(5):1012-7. https://doi.org/10.1136/ijgc00009577-200409000-00040

82. Lee E-S, Kim I. Multiple Vulvar Lactating Adenomas. Obstet Gynecol. 2011;118(2):478-80. https://doi. org/10.1097/AOG.0b013e31821 ecaa2

83. Hong JH, Oh MJ, Hur JY, Lee JK. Accessory breast tissue presenting as a vulvar mass in an adolescent girl. Arch Gynecol Obstet. 2009;280(2):317-20. https:// doi.org/10.1007/s00404-008-0905-z

84. Piura B, Gemer O, Rabinovich A, Yanai-Inbar I. Primary breast carcinoma of the vulva: case report and review of literature. Eur J Gynaecol Oncol. 2002;23(1):21-4. Disponible en: http://www.ncbi. nlm.nih.gov/pubmed/11876386

85. Kais M, Bitterman-Deutsch O, Schwaartz J, Oettinger M, Cohen I. Phyllodes tumor in aberrant breast tissue of the vulva. Cervix Low Female Genital Tract. 1995;13:3:(105-106).
86. Baradwan S, Wadi K Al. Unilateral ectopic breast tissue on vulva in postpartum woman. Medicine (Baltimore). 2018;97(6):e9887. https://doi.org/10.1097/ MD.0000000000009887

87. Al-Badawi IA, Al-Sabban M. Unilateral Ectopic Mammary-Like Tissue in the Vulva. J Obstet Gynaecol Canada. 2014;36(11):951. https://doi.org/10.1016/ S1701-2163(15)30403-5

88. Mannan AASR, Kahvic M, Abdel Aziz AH. Phyllodes Tumor of the Vulva: Report of a Rare Case and Review of the Literature. Am J Dermatopathol. 2010;32(4):384-6. https://doi.org/10.1097/ DAD.0b013e3181bfce84

89. Kapila K, Al-Rabah NA, Junaid TA. Ectopic breast tissue on the vulva diagnosed by fine needle aspiration. Acta Cytol. 1998;42(6):1480-94. Disponible en: https://www.karger.com/Article/FullText/332190

90. Neumann I, Strauss HG, Buchmann J, Koelbl H. Ectopic lobular breast cancer of the vulva. Anticancer Res. 20(6C):4805-8. Disponible en: http://www.ncbi. nlm.nih.gov/pubmed/11205223

91. Scarabin C, Koskas M, Bornes M, Azria E, Luton D. Gigantomastia and vulvar lactating adenoma in a patient with myasthenia during pregnancy. Am J Obstet Gynecol. 2010;203(4):e5-8. https://doi. org/10.1016/j.ajog.2010.07.001

92. Matak L, Dukić B, Tupek T, Lisica-Šikić N, Mikuš M. Primary ectopic lobular breast cancer of the vulva: case report and review of literature. J Obstet Gynaecol (Lahore). 2020;40(5):727-30. https://doi.org/10.10 80/01443615.2019.1623182

93. Mayer RB, Enengl S, Witzany H, Trautner P, Shebl O, Oppelt P. Postpartum Galactostasis of the Vulva in a Case of Bilateral Lactating Ectopic Breast Tissue. Obstet Gynecol. 2019;134(1):138-40. https://doi. org/10.1097/AOG.0000000000003313

94. Sluga M. Uncommon vulvar lesions. J Low Genit Tract Dis. 2017;21:4(Supplement 1 (S27-)). https://doi. org/10.1097/LGT.0000000000000335

95. Leodara V, Karabogias C, Filis C, Kakiopoulos G, Papaliodi E. Vulva, a rare site of Phyllodes tumour: a case report. Virchows. Disponible en: Science Citation Index.

96. Giger OT, Lacoste E, Honegger C, Padberg B, Moch H, Varga Z. Expression of the breast differentiation antigen NY-BR-1 in a phyllodes tumor of the vulva. 
Virchows Arch. 2007;450(4):471-4. https://doi. org/10.1007/s00428-007-0377-8

97. Abstracts from 18th International Meeting of the European Society of Gynaecological Oncology (ESGO), 19-22 October 2013, Liverpool, UK. Int J Gynecol Cancer. 2013;23(Supp 1):1-1281. https://doi. org/10.1097/01.IGC.0000437414.49882.6a

98. Gorisek B, Zegura B, Kavalar R, But I, Krajnc I. Primary breast cancer of the vulva: a case report and review of the literature. Wien Klin Wochenschr. 2000;112(19):855-8. Disponible en: http://www. ncbi.nlm.nih.gov/pubmed/11098538

99. Dordević M, Jovanović B, Mitrović S, Dordević G. Ectopic mammary tissue in vulva. Vojnosanit Pregl. 2008;65(5):407-9. https://doi.org/10.2298/ VSP0805407D

100. Tapia Claro I, Soriano Torres O M de OI. Fibroadenoma como causa de tumor en la vulva. Presentación de caso. Rev Habanera Ciencias Médicas. 2020;19((3):e3094.):1-8. https://doi. org/10.1186/1477-7819-7-70

101. Cantú de Leon D, Perez Montiel D, Vázquez H, Hernández C, Cetina L, Lucio M. Vulvar fibroadenoma: a common neoplasm in an uncommon site. World J Surg Oncol. 2009;7(1):70. Disponible en: http://wjso.biomedcentral.com/ articles/10.1186/1477-7819-7-70

102. Ahmed S, Ding CSL, Shelat VG. Ectopic breast tissue in the vulva masquerading as an abscess. Am J Physiol Regul Integr Comp Physiol. 2020;133(1515):281-2. https://doi.org/10.11622/smedj.2018121

103. Mohammadnia Avval M, Vijayananda Kumar P, Momtahan M. Fine-needle aspiration findings of fibroadenoma with pseudolactational changes in the vulva: A case report. Diagn Cytopathol. 2020;48(12). https:// doi.org/10.1002/dc. 24527

104. Naseer MA, Mohammed SS, George SM, Majumdar SK Das. Primary ectopic breast cancer mimicking as vulval malignancy. J Obstet Gynaecol (Lahore). 2011;31(6):553-4. https://doi.org/10.3109/01443 615.2011 .587054
105. Anunobi CC, Obiajulu FJN, Banjo AAF, Okonkwo AOE. Vulva Fibroadenoma Associated with Lactating Adenoma in a 26-Year-Old Nigerian Female. Case Rep Pathol. 2013;2013:1-3. https://doi. org/10.1155/2013/195703

106. Dhaoui A, Nfoussi H, Kchir N, Haouet S. Vulvar lactating adenoma associated to a fibroadenoma: common neoplasms in an uncommon site. Pan Afr Med J. 2012;13:47. Disponible en: http://www.ncbi.nlm. nih.gov/pubmed/23330038

107. Lopes A, St. Louis J, Balancin ML, Nogueira-Rodrigues A, Silva LCFF, Paulino E, et al. A Rare Presentation of Primary Breast Carcinoma in the Vulva: A Case Report and Literature Review. Clin Breast Cancer. 2018;18(3):e291-4. https://doi.org/10.1016/j. clbc.2017.06.004

108. Jiménez GA VA. Fibroadenoma vulvar: reporte de un caso y revisión de la literatura. MÉD UIS. 2014;27(27(2)):93-6.

109. Guzmán P, Jarufe F, Castagnoli N. Fibroadenoma vulvar: A propósito de un caso clínico. Rev Chil Obstet Ginecol. 2019;84(2):142-6. https://doi.org/10.4067/ S0717-75262019000200142

\section{FINANCIACIÓN}

Los autores no recibieron ninguna fuente de financiación.

\section{CONTRIBUCIÓN DE LAS AUTORAS}

Sandra Marcela Buitrago-Flechas: diseño y elaboración del manuscrito, revisión bibliográfica y aprobación de la versión final.

Sandra Johana Barrera-Latorre: revisión de la literatura y contenido intelectual.

Carolina Morante-Caicedo: diseño y elaboración del manuscrito, revisión bibliográfica y aprobación de la versión final. Diseño de material gráfico. 